\title{
Las orientaciones del mediador: análisis de la mediación en Quito*
}

\author{
Ximena Bustamante** \\ María Bernarda Carpio Frixone $e^{* * *}$ \\ Isabela Moreno ${ }^{* * * *}$ \\ María Gracia Naranjo Ponce ${ }^{* * * * *}$
}

Recibido/Received: 29/07/2017

Aceptado/Accepted: 31/07/2017

SUMARIO: 1. Un acercamiento a la mediación. 2. Reconocimiento de la mediación en el marco normativo ecuatoriano. 3. La orientación de la mediación. 3.1 Estilos del mediador. 3.1.1 Estilo facilitativo. 3.1.2 Estilo evaluativo. 3.2 Enfoque sobre la definición del problema. 3.3 Las cuatro orientaciones en la mediación. 3.3.1 El mediador facilitativo con una visión estrecha del problema. 3.3.2 El mediador facilitativo con una visión amplia del problema. 3.3.3 El mediador evaluativo con una visión estrecha del problema. 3.3.4 El mediador evaluativo con una visión amplia del problema. 3.4 ¿Se mueven los mediadores en las orientaciones? ¿En qué momento? 4. Revisión de estilos y definición del problema en la mediación en la ciudad de Quito. 4.1 Metodología de investigación. 4.2 Estilos de mediación en la ciudad de Quito. 4.3 Definición del

* Agradecemos al Colegio de Jurisprudencia de la Universidad San Francisco de Quito, porque en el marco de sus programas de investigación, impulsó el desarrollo de este trabajo.

** Socia de PACTUM Dispute Resolution Consulting, Profesora de la Universidad San Francisco de Quito y ex Directora Nacional de Mediación de la Procuraduría General del Estado y Subdirectora del Centro de Arbitraje y Mediación de la Cámara de Comercio de Quito. Abogada por la Universidad San Francisco de Quito, LL.M. en Resolución de Disputas del Straus Institute for Dispute Resolution de la Universidad de Pepperdine, Weinstein International Fellow por la Fundación JAMS.

*** Estudiante de Jurisprudencia con subespecialización en manejo de conflictos. Universidad San Francisco de Quito.

**** Estudiante de Jurisprudencia. Universidad San Francisco de Quito.

***** Estudiante de Jurisprudencia y Relaciones Internacionales. Universidad San Francisco de Quito.

X. Bustamante, M. B. Carpio Frixone, I. Moreno y M. G. Naranjo Ponce, "Las orientaciones del mediador: análisis de la mediación en Quito", Revista Ecuatoriana de Arbitraje, No. 8, 2016. 
problema en la ciudad de Quito. 4.4. Las orientaciones de la mediación en la ciudad de Quito. 4.5. Otras técnicas procedimentales relevantes empleadas en la ciudad de Quito. 5. Conclusiones.

PALABRAS CLAVE: Estilos de mediación, definición del problema, definición amplia del problema, definición estrecha del problema, estilo evaluativo, estilo facilitativo.

KEYWORDS: Mediation styles, problem definition, broad problem definition, narrow problem definition, evaluative style, facilitative style.

RESUMEN: El presente trabajo expone las características de los estilos de mediación facilitativo y evaluativo; y de la visión que el mediador puede adoptar sobre el problema sometido a mediación: amplia y estrecha. Así, examina las cuatro posibles orientaciones que puede seguir el mediador: facilitativo con una visión estrecha del problema; facilitativo con una visión amplia del problema; evaluativo con una visión estrecha del problema; y evaluativo con una visión amplia del problema. Posteriormente, se identifica el estilo de mediación y la definición del problema con mayor uso en la ciudad de Quito, así como aquellos preferidos por los abogados que asisten a mediaciones. Para ello, se realizaron encuestas tanto a mediadores como a abogados de la ciudad de Quito a fin de determinar el estilo y la definición del problema por la cual se orientan e identificar la situación actual de la mediación en Quito.

ABSTRACT: This paper exposes the characteristics of the facilitative and evaluative mediation styles; and of the vision that the mediator can adopt over the problem submitted to mediation: broad and narrow. Thus, it examines the four possible orientations that the mediator can follow: facilitative with a narrow view of the problem; facilitative with a broad vision of the problem; evaluative with a narrow view of the problem; and evaluative with a broad vision of the problem. Later, this research identifies the style of mediation and the 
definition of the problem with greater use in the city of Quito, as well as the ones preferred by the lawyers who attend mediations. To this end, surveys were carried out to both mediators and lawyers from the city of Quito in order to determine the style and view of the problem to which they are oriented and to identify the current situation of mediation in Quito.

\section{UN ACERCAMIENTO A LA MEDIACIÓN}

Los métodos alternativos de solución de conflictos son aquellos que resuelven controversias sin la necesidad de acudir al proceso judicial. Los métodos típicos incluyen: evaluación neutral, negociación, conciliación, mediación y arbitraje ${ }^{1}$. Estos se encuentran sustentados en principios de entendimiento y cooperación mutua para así arreglar un conflicto de forma pacífica²

El término "mediación" puede tener distintos significados dependiendo del contexto en el que se utiliza o dependiendo si el énfasis está en el procedimiento o en el resultado ${ }^{3}$. Sin embargo, con el afán de dar forma a lo que la mediación concentra, ésta ha sido definida como "(...) un procedimiento no adversarial, donde un tercero neutral -el mediador- conduce un proceso de negociación, asistiendo a las partes para que arriben a un acuerdo" ${ }^{\prime 4}$. La mediación se mira como un procedimiento informal alternativo al litigio, en donde profesionales en negociación ayudan a que las partes conjuntamente lleguen a un acuerdo ${ }^{5}$.

La mediación tiene como característica esencial la voluntariedad y el consentimiento de las partes para participar. Adicionalmente, los mediadores actúan como terceros neutrales que

1. Legal Information Institute, Mediation, «https://www.law.cornell.edu/wex/alternative_dispute_resolution».

2. M. GonZALo et al., Métodos alternos de solución de conflictos Herramientas de paz y modernización de la justicia, Ed. DYKINSON, S.L., 2011, p. 32.

3. LaW Reform Commission, Alternative dispute resolution: Mediation and Conciliation, 2010, p. 19.

4. O. GoZAínI, "La mediación y el arbitraje en Argentina: situación actual", THEMIS Revista de Derecho, No. 43, 2001, p. 99.

5. LEGAL INFORMation InSTITUTE, N. 1. 
construyen un marco de cooperación entre las partes, para que sean éstas las que lleguen a un acuerdo 6 . "Con la mediación se persigue incorporar la denominada justicia coexistencial, donde el órgano actuante "acompañe" a las partes en su conflicto, orientándolas con su consejo en la búsqueda racional de respuestas superadoras de la crisis" ${ }^{\prime 7}$. Así también, la mediación es concebida como un espacio confidencial, dando a las partes la oportunidad de hablar libremente y realizar propuestas de resolución en la confianza que ello no afectará un eventual proceso judicial posterior.

Lo que finalmente pretende la mediación es que las partes lleguen a un acuerdo ${ }^{8}$, sea que éste se adecúe a la solución normativa, o no necesariamente, como se desarrolla más adelante:

[L]a mediación parte de una premisa diferente. No se trata de conciliar intereses opuestos que miran una misma situación (contractual o de hecho); sino de encontrar una respuesta pacífica, una alternativa flexible que no tenga el marco preciso de la perspectiva analizada, pudiendo conseguir resultados absolutamente diferentes del cuadro típico que califica la pretensión y su resistencia?.

\section{RECONOCIMIENTO DE LA MEDIACIÓN EN EL MARCO NORMATIVO ECUATORIANO}

La mediación fue reconocida en el marco jurídico ecuatoriano a partir de la promulgación de la Ley de Arbitraje y Mediación. Esta ley especializada derogó la Ley de Arbitraje Comercial (que fue promulgada el 28 de octubre de 1963). Así, se pasó de una ley que tan solo regulaba el arbitraje a una que regula ambos mecanismos ${ }^{10}$.

6. O. Gozaíni, N. 4 (2001).

7. O. GozAínI, La mediación: una nueva metodología para la resolución de controversias, Congreso Internacional de Derecho Procesal, 2009.

8. O. Gozaíni, N. 4 (2001), p. 100.

9. O. Gozaíni, Formas Alternativas para la Resolución de Conflictos, Ed. Depalma, 1995, p. 15.

10. La promulgación de esta ley es fruto del impulso generado por el Banco Mundial y el Banco Interamericano de Desarrollo. En su afán por generar programas de reforma judicial, ambas instituciones 
La Constitución de 1998 siguió la tendencia de reconocimiento de la mediación en el país. Así, en su artículo 91 prescribió que "[s]e reconocerán el arbitraje, la mediación y otros procedimientos alternativos para la resolución de conflictos, con sujeción a la ley". De igual manera, la actual Constitución ratificó este reconocimiento al plasmar en su artículo 190 que "[s]e reconoce el arbitraje, la mediación y otros procedimientos alternativos para la solución de conflictos"11.

Por otro lado, el Código Orgánico de la Función Judicial, promulgado en 2009, establece en su artículo 17 que "[...] [e]l arbitraje, la mediación y otros medios alternativos de solución de conflictos establecidos por la ley, constituyen una forma de este servicio público [de administración de justicia], al igual que las funciones de justicia que en los pueblos indígenas ejercen sus autoridades $[\ldots]^{\prime \prime 2}$.

Así pues, a partir de la promulgación de la Ley de Arbitraje y Mediación, la mediación ha tenido un mayor reconocimiento normativo, incluso de rango constitucional.

Ante esto, el Plan Estratégico de la Función Judicial establece como uno de sus objetivos el "promover el óptimo acceso a la justicia". Así, determina que dentro de las estrategias a tomar para alcanzar este objetivo es indispensable:

[...]2.6 Crear centros de mediación y juzgados de paz a nivel nacional fomentando una cultura de paz y de diálogo para solucionar los conflictos;

2.7 Fortalecer el mecanismo de derivación al interior de los juzgados hacia instancias alternativas de resolución de conflictos; $y$

2.8 Potenciar el uso de la conciliación judicial ${ }^{13}$.

promovieron propuestas para difundir el uso de medios alternativos de solución de conflictos. G. PoVEDA. Medios Alternativos de Solución de Conflictos en Ecuador: La Mediación. Tesis de Grado. Universidad Andina Simón Bolívar, 2006, p. 10.

11. Constitución Política de la República del Ecuador, Ar. 191, RO No. 1, 11/08/98.

12. Código Orgánico de la Función Judicial, Art. 17, RO Sup. No. 544, 09/03/09.

13. Consejo De la Judicatura. Plan Estratégico de la Función Judicial, p. 41, «http://www.funcionjudicial.gob.ec/www/pdf/PLANESTRATEGICOFJ.pdf». 
De este modo se constata la prioridad que en Ecuador se da a la mediación como un método adecuado para la solución de controversias y en especial como una vía para alcanzar un óptimo acceso a la justicia. El establecer la necesidad de fortalecer la mediación es a su vez un llamado a la comunidad para que emplee este mecanismo y para los profesionales tanto mediadores como abogados para que amplíen el concepto tradicional de la mediación y la desarrollen a través de la práctica.

\section{LA ORIENTACIÓN DE LA MEDIACIÓN}

Ahora bien, ¿qué es exactamente lo que hace el mediador? ¿Cómo logra facilitar la comunicación y guiar la negociación para que las partes alcancen un acuerdo?

La respuesta a estas interrogantes depende principalmente de la visión que tengan el mediador, las partes y los abogados que las acompañan, sobre cómo debe ser la mediación. A esta visión la llamamos orientación y se compone de dos conceptos importantes. El primero concepto es el estilo del mediador y el segundo es la definición del problema.

LEONARD RISKIN ha definido a los estilos facilitativo y evaluativo como opuestos en cuanto a lo que el mediador hace. Igualmente considera que la definición del problema puede ser distributiva o estrecha en contraposición a integrativa o amplia en función de la profundidad con la que se aborde la controversia. ${ }^{14}$

Con el objetivo de explicar aquello con mayor profundidad, en la presente sección se analizarán los estilos del mediador [3.1] y los distintos enfoques que existen respecto a la definición del problema [3.2]. Sobre la base de ello se expondrán las cuatro posibles orientaciones en la mediación [3.3] y finalmente se estudiará la viabilidad de que los mediadores cambien de orientación a lo largo del procedimiento [3.4].

14. L. Riskin, "Mediator Orientations, Strategies and Techniques", Alternatives, Vol. 12 (9), 1994, p. 111. 


\subsection{Estilos del mediador}

Los estilos de mediación tienen que ver con la aproximación que el mediador tenga al manejo del procedimiento. Estas aproximaciones pueden ser facilitativas [3.1.1] o evaluativas [3.1.2], dependiendo del alcance de las facultades que el mediador se atribuye dentro del procedimiento.

El mediador facilitativo se centra en moderar la participación de las partes en la audiencia, explorar en conjunto con ellas sus verdaderos intereses, y guiarlas a través de preguntas para que ellas mismas encuentren la solución apropiada para su controversia. Desde la visión facilitativa, el mediador es un réferi en el juego en el que participan únicamente las partes, e interviene lo menos posible para no afectar el resultado de su procedimiento.

Al contrario, el mediador evaluativo busca intervenir activamente en la resolución de la controversia. Para ello se atreve a realizar predicciones sobre lo que pasaría si no se llega a un acuerdo, evaluar las debilidades de la posición de las partes, sugerir fórmulas de acuerdo e inclusive instar a las partes a aceptarlas. Desde la visión evaluativa, el mediador es casi otro jugador que cambia la dinámica del juego, e interviene activamente sin perder su neutralidad.

\subsubsection{Estilo facilitativo}

Se dice que el estilo facilitativo es la esencia de la mediación, esto en razón de que en los inicios de la mediación, el único estilo que se enseñaba y practicaba era el que ahora llamamos facilitativo ${ }^{15}$. Donde la mediación es un proceso de diálogo, que se encuentra diseñado para que sean las mismas partes las que identifiquen y den forma a la solución que vean más conveniente $^{16}$.

15. Z. ZumetA, "Styles of Mediation: Facilitative, Evaluative, and Transformative Mediation", «http://www.mediate.com/articles/zumeta.cfm» (02/04/2017).

16. C. Brown, "Facilitative Mediation: The Classic Approach Retains its Appeal", Mediate, «http://www.mediate.com/articles/brownc.cfm» (03/04/2017). 
De acuerdo a CAROLE J. BROWN este estilo se basa en tres principios fundamentalmente: (i) la autodeterminación de las partes para la resolución de la disputa; (ii) la neutralidad del tercero facilitador; y, (iii) el tercero es aquel que facilita la comunicación entre las partes, para que ellas puedan entender mutuamente sus intereses y encuentren una solución creativa ${ }^{17}$.

RISKING describe a la mediación facilitativa como aquella en donde el mediador asume que las partes son inteligentes, que pueden trabajar en conjunto con su contraparte y que son capaces de entender y asimilar su situación mejor que el mediador, e incluso, mejor que sus abogados. Las soluciones que las partes pueden dar son más adecuadas que la solución que cualquier otro pudiese dar. Dado lo anterior, un mediador facilitativo tiene como misión principal el clarificar los puntos de discusión y mejorar la comunicación entre las partes, ${ }^{18}$ para que ellas decidan qué solución dar a su problema.

Consecuentemente, el papel del mediador facilitativo se encuentra fuertemente limitado. El mediador se encarga del procedimiento como tal, pero son las partes las que deben llegar a una solución ${ }^{19}$. El mediador estructura el procedimiento y se abstiene de plantear recomendaciones $\mathrm{u}$ opiniones respecto de la controversia $^{20}$. Las partes crean y alcanzan acuerdos y soluciones por sí mismas, con la presencia de un tercero que finalmente es sólo esto, uno más presente en la sala.

El mediador facilita las cosas para que los que asisten a la audiencia puedan hablar francamente de sus intereses, dejando de lado sus posiciones adversas. Mediante las preguntas apropiadas y las técnicas adecuadas, se puede llevar a las partes hacia los puntos de coincidencia y, si ellas no llegan a un acuerdo, el mediador no puede tomar ninguna decisión al respecto porque él no puede obligarlas a hacer o aceptar nada ${ }^{21}$.

17. C. Brown, N. 16 .

18. C. Brown, N. 16.

19. S. NAuss EXON, "The Effects that Mediator Styles Impose on Neutrality and Impartiality Requirements of Mediation", University of San Francisco Law Review, Vol. 42, p. 579.

20. Z. ZuMETA, N. 15.

21. O. Gozaíni, N. 9 (1995). 
La función del mediador facilitativo, según Osvaldo GoZAíNI, implica 5 cuestiones: (i) facilitar la comunicación para que las partes se escuchen; (ii) ordenar las pretensiones de las partes sobre la base de necesidades e intereses; (iii) consolidar los puntos o necesidades que las partes tienen en común; (iv) trabajar sobre los puntos de controversia; $y$, (v) asegurarse que ambas partes conozcan sus derechos ${ }^{22}$. Para ello el mediador delimita su participación en la conversación a realizar preguntas, validar y normalizar las opiniones de cada una de las partes, explorar los verdaderos intereses de las partes y asistirlas para que sean ellas las que lleguen a una solución por medio de brainstorming ${ }^{23}$.

Se ha considerado que el estilo facilitativo evoca lo que realmente es la mediación, pues permite a las partes llegar a un acuerdo, satisfaciendo sus intereses, empoderándolas, y brindándoles de alguna forma un método terapéutico ${ }^{24}$. Sin embargo, entre las críticas a este estilo se considera que el mediador es demasiado pasivo, lo que puede dificultar el alcance del acuerdo. Así también, su pasividad puede crear un desbalance entre las partes, perjudicando al débil. Incluso se dice que si el mediador intenta equilibrar la situación de poder entre las partes, estaría violando la imparcialidad del procedimiento ${ }^{25}$.

\subsubsection{Estilo evaluativo}

Dentro del espectro de los estilos del mediador, en el lado opuesto al estilo facilitativo se encuentra el evaluativo. En este estilo el mediador interviene en mayor grado, evaluando las cuestiones legales, los derechos de las partes y/o sus intereses y posiciones $^{26}$.

22. O. Gozaíni, N. 9.

23. S. NAuSs ExON, "Effects That Mediator Styles Impose on Neutrality and Impartiality Requirements of Mediation", University of San Francisco Law Review, Vol. 42, 2007, p. 939.

24. K. Roberts. "Mediating the Evaluative-Facilitative Debate: Why Both Parties Are Wrong and a Proposal for Settlement”, Loyola University Chicago Law Journal, Vol. 39 (1), 2007, p. 193.

25. S. NAUSS EXON, N. 23, p. 602.

26. C. Moore y N. Kemp. The mediation process: Practical strategies for resolving conflict, Jossey-Bass, 1998, p. 56. 
El término 'evaluación' se refiere al proceso mediante el cual un tercero neutral expresa su opinión acerca de los posibles resultados de un conflicto legal en caso de que éste vaya a ser resuelto en una corte ${ }^{27}$. El objetivo del mediador en este caso es ofrecer a las partes la visión de un tercero neutral que les permita ver más allá de su propia postura. Si bien su intervención tiende a enfocarse en asuntos legales o procedimentales, los mediadores evaluativos también podrían tomar una postura similar -ofrecer consejos, predicciones, o sugerir soluciones- acerca de temas sustantivos o incluso relacionales.

De acuerdo a Dwight Golann y Marjorie CORMAN AARON, un mediador evaluativo puede lograr cambiar las percepciones y evaluaciones que las partes tienen sobre sus posturas y alternativas. Cuando un conflicto se resuelve por medio de los métodos ordinarios de justicia, ambas partes predicen que tienen altas posibilidades de ganar. Dentro de una mediación, si estos niveles altos se mantienen, se dificulta que las partes desarrollen las negociaciones de buena fe y alcancen acuerdos beneficiosos para $\operatorname{ambas}^{28}$.

La evaluación puede cortar los juicios erróneos que tienen las partes acerca de los méritos del caso. Cuando las partes escuchan que un tercero neutral -después de estudiar los hechos del caso y escuchar los argumentos de las partes- no concuerda con sus predicciones de victoria, se motivan a evaluar nuevamente su caso y preguntarse qué es lo que el evaluador ha podido ver y la parte no $^{29}$.

Algunos académicos se han referido a los mediadores evaluativos como 'mediadores directivos' o 'mediadores con músculo'. El hecho de que el mediador ofrezca una evaluación personal del conflicto y de sus posibles resultados implica que

27. D. Golann y M. Corman, "Using evaluations in mediation”. Citado en: AAA Handbook on Mediation, American Arbitration Association, p. 328.

28. Ídem, p. 329.

29. Traducción libre. Ídem, p. 330. Texto original: Evaluation can cut through litigants' misjudgments about the merits of a case. When disputants hear that a neutral person, after studying the facts and listening to the arguments, disagrees with their predictions of victory, they are motivated to look again at the case and ask what the evaluator has seen that they have not. 
ejerza un cierto grado de influencia sobre las partes ${ }^{30}$. En todo caso, la actividad del mediador evaluativo no debe nunca imponer una postura propia.

Así pues, en lugar de limitarse a facilitar la comunicación entre las partes sin ejercer influencia alguna sobre ellas; un mediador evaluativo cuestiona los puntos en discusión, ofrece consejos procedimentales y sustantivos, predice resultados y sugiere formas de solucionar el conflicto ${ }^{31}$. CHRISTOPHER MOORE explica que

[...] los mediadores evaluativos también llevan a cabo pruebas de realidad con las partes, para descubrir los posibles vacíos en su entendimiento, aclarar las debilidades de los argumentos, identificar cómo la ley o la jurisprudencia no benefician a la posición de la parte, superar las evaluaciones irracionales, favorecer las evaluaciones más realistas de los casos, recordarles acerca de sus intereses subyacentes y a largo plazo, y determinar los potenciales costos y beneficios de solucionar el conflicto o no hacerlo ${ }^{32}$.

En consecuencia, son actitudes comúnmente asumidas por los mediadores evaluativos: (i) emitir un criterio jurídico para ayudar a entender las fortalezas y debilidades de las partes; (ii) darles una opinión acerca del posible resultado del conflicto si este fuese llevado a las cortes; (iii) dar sugerencias a las partes acerca de las mejores alternativas para solucionar el problema; (iv) proponer opciones de solución que satisfagan los intereses de las partes; y, (v) sugerir una particular propuesta de solución a las partes. Los mediadores evaluativos utilizan principalmente reuniones privadas donde pueden hablar libremente con las partes sobre las debilidades de su caso. Adicionalmente, un mediador evaluativo debe tener cierto grado de experiencia en la materia sobre la cual versa la disputa a fin de cumplir las actividades antes mencionadas.

30. S. Nauss Exon, N. 23, p. 593.

31. Ídem, p. 592.

32. Traducción libre. C. Moore y N. Kemp, N. 26, p. 56. Texto original: Evaluative mediators also commonly conduct reality testing with parties to uncover gaps in understanding, clarify weaknesses in arguments, identify where the law or past legal cases do not support a party's views, overcome irrational assessments, encourage more realistic appraisals of parties' cases, remind them of their underlying and long-term interests, and determine the potential benefits and costs of settling or not. 
Ahora bien, la mediación evaluativa ha recibido también algunas críticas. Entre las principales se encuentra que el mediador puede comprometer su neutralidad e imparcialidad, así como disminuir la autodeterminación y autonomía de las partes, impedir su empoderamiento a largo plazo, y aumentar los niveles de confrontación entre las mismas. Para algunos, la 'mediación con músculo' implica necesariamente un grado de coerción por un tercero, por lo que se aleja de la esencia misma de la mediación, que es la persuasión mas no la coerción ${ }^{33}$. De manera similar, las profesoras KiMBERLEE KOVACH y LELA LOVE se refieren a la mediación evaluativa como un oxímoron ${ }^{34}$, sosteniendo que la esencia de la mediación y la evaluación por parte del mediador no son concordantes, dado que la imparcialidad y neutralidad son elementos fundamentales.

La mediación evaluativa es un oxímoron. Pone en riesgo a la neutralidad porque la evaluación del mediador invariablemente favorece a una de las partes por sobre la otra. Adicionalmente, las actividades evaluativas disuaden el entendimiento entre las partes, y la solución del problema por parte de las mismas. En lugar de ello, la evaluación del mediador tiende a perpetuar o crear un clima de confrontación ${ }^{35}$.

\subsection{Enfoque sobre la definición del problema}

Además del estilo que pueda tener un mediador, existe otro factor por el que se puede orientar la mediación. Esto consiste en la visión que se tenga sobre el problema a abordar, misma que puede ser estrecha o amplia.

33. K. SkJelsbaeK, "The UN Secretary-General and the mediation of international disputes", Journal of Peace Research, Vol. 28(1), 1991. Citado por J.D. Sмітн, "Mediator impartiality: banishing the Chimera", Journal of Peace Research, 1994.

34. Combinación, en una misma estructura sintáctica, de dos palabras o expresiones de significado opuesto que originan un nuevo sentido, como en un silencio atronador (Real Academia Española de la Lengua)

35. Traducción libre. K. K. Kovach y L. P. Love, “Evaluative' mediation is an oxymoron”, Alternatives to the High Cost of Litigation, Vol. 14, No. 3, 1996, p. 31. Texto original: "Evaluative" mediation is an oxymoron. It jeopardizes neutrality because a mediator's assessment invariably favors one side over the other. Additionally, evaluative activities discourage understanding between and problem-solving by the parties. Instead, mediator evaluation tends to perpetuate or create an adversarial climate". 
La definición del problema se da en función del contenido que se entiende tendría el conflicto. Así pues el conflicto puede versar sobre los aspectos (i) litigiosos; (ii) comerciales; (iii) personales; y, (iv) comunitarios ${ }^{36}$. "Una visión sumamente estrecha del problema se enfoca principalmente en los derechos litigiosos, pero mientras el espectro se amplía puede incluir aspectos comerciales, personales o cuestiones de la relación entre las partes" ${ }^{\prime \prime 2}$.

En el primer nivel, la mediación se enfoca casi exclusivamente en las pretensiones de las partes desde una perspectiva legal. Los mediadores que tienen este tipo de perspectiva centran la mediación en un análisis de las alternativas que tendría cada parte en caso de ir a un proceso judicial. Así, un mediador con una visión estrecha del problema mirará el posible resultado del conflicto si este fuese llevado a las cortes para evitar los riesgos de un eventual resultado desfavorable, y no dará mayor importancia a los asuntos anexos a la controversia, como intereses, emociones o causas del conflicto. En este sentido, LEONARD RISKIN sostiene que en un enfoque estrecho:

El principal objetivo es resolver la disputa a través de un acuerdo que se aproxime al resultado que se obtendría en la vía procesal, como sería un juicio, sin la demora o los gastos que implica el uso de esta alternativa. La cuestión más importante suele ser el probable resultado del litigio ${ }^{38}$.

El segundo nivel se enfoca en temas comerciales o del negocio. En consecuencia, la discusión se centra en aspectos que no serían tomados en consideración dentro de un proceso judicial. LEONARD RISKIN grafica aquello a través del siguiente ejemplo:

36. K. ROBERTS, N. 24, p. 193.

37. Ídem, p. 189. Texto original: "The narrowest approach focused primarily on legal issues, but as the spectrum became broader, business, personal, relational, and community interests were also included".

38. Traducción libre. L. RISKIN, "Understanding mediators' orientations, strategies, and techniques: A grid for the perplexed", Harvard Negotiation Law Review, No. 1 (7), 1996, p. 19. Texto original: "the primary goal is to settle the matter in dispute though an agreement that approximates the result that would be produced by the likely alternative process, such as a trial, without the delay or expense of using that alternative process. The most important issue tends to be the likely outcome of litigation". 
[...] es posible que Golden State esté disconforme con la estructura general de tarifas o con el desempeño de Computec $^{39}$ en la ejecución del contrato; y la mediación puede abordar estas preocupaciones. Al reconocer el interés mutuo de las partes en mantener una buena relación comercial, en parte porque son mutuamente dependientes, las partes pueden hacer ciertos ajustes al contrato. Al ampliar un poco el enfoque es posible que la mediación considere aspectos comerciales que son fundamentales, tales como el hecho de que ambas compañías necesitan continuar con el negocio, obtener rentabilidad y desarrollar y mantener una buena reputación. Una mediación en estos términos conlleva a un acuerdo que además de resolver la cuestión alrededor de los US\$ 30,000 desarrolla un plan de colaboración en el nuevo negocio. Así, al explorar sus intereses comerciales mutuos ambas compañías tienen la oportunidad de mejorar su situación de una forma en la que no lo hubiesen concebido desde otro enfoque ${ }^{40}$.

\section{El tercer nivel, hacia una visión más amplia del problema,} gira en torno a aspectos personales de cada una de las partes. El objetivo no es exclusivamente solucionar el conflicto, sino que

39. El caso Golden State y Computec es el siguiente: Golden State Savings \& Loan NTC (la segunda mayor asociación de ahorros y préstamos en el estado) contrató con Computec (una consultora informática). El objeto del contrato era que Computec organice e informatice su sistema de procesamiento de datos. Golden State acordó pagar a Computec una comisión anual de consultoría y administración. Al finalizar el primer año, Computec presentó a Golden State una factura por aproximadamente US\$ 30,000 que representaba los costos incurridos por el personal de Computec en asistir a seminarios y reuniones relacionados con la instalación de tecnología informática en los bancos y los costos incurridos al reunirse con varios consultores externos sobre aspectos del contrato con Golden State. Golden State señaló que al no existir en el contrato ningún término expreso que permita el reembolso de estos cargos, y porque el banco tenía una política estricta contra el reembolso de tales gastos no reembolsaría al personal de Computec. Computec respondió rápidamente, informando a Golden State que este tipo de cargo era universalmente reembolsado por el comprador de servicios de consultoría informática, y que seguiría buscando a Golden State para su reembolso. El conflicto está generando sentimientos de enojo entre estas dos empresas, que deben trabajar en estrecha colaboración durante varios años. Véase, L. Riskin, N. 38, pp. 17-18.

40. Traducción libre. L. Riskin, N. 38, p. 19. Texto original: "For example, it might be that Golden State is displeased with the overall fee structure or with the quality or quantity of Computec's performance under the contract, and the mediation might address these concerns. Recognizing their mutual interest in maintaining a good working relationship, in part because they are mutually dependent, the companies might make other adjustments to the contract. Broadening the focus a bit, the mediation might consider more fundamental business interests, such as both firms' need to continue doing business, make profits, and develop and maintain a good reputation. Such a mediation might produce an agreement that, in addition to - disposing of the \$30,000 question, develops a plan to collaborate on a new business venture, Thus, by exploring their mutual business interests, both companies have the opportunity to improve their situations in ways they might not have considered but for the negotiations prompted by the dispute". 
este enfoque brinda a las partes la oportunidad de aprender y cambiar a través de la resolución del conflicto. Así,

[...] las partes pueden reparar su relación aprendiendo a perdonarse una a otra o reconociendo su conexión. Las partes pueden aprender a entenderse, a renunciar a su ira o al deseo de venganza, a trabajar por la paz interior, o superarse a ellos mismos. También pueden aprender a vivir de acuerdo con las enseñanzas o valores de la comunidad a la que pertenecen ${ }^{41}$.

Así, usando el mismo ejemplo empleado para demostrar el enfoque en temas comerciales, LEONARD RISKIN sostiene que:

En el tercer nivel la mediación se enfoca en cuestiones más personales. Por ejemplo, en la resolución de la disputa de los US\$30,000, es posible que los ejecutivos de cada compañía tengan una actitud hostil entre ellos o que se hayan sentido insultados unos a otros. Esta hostilidad puede producir ansiedad y pérdida de autoestima ${ }^{42}$.

En efecto, en una mediación enfocada en temas personales se procurará un proceso de cambio en las partes de suerte que mediante la mediación logren ventilar sus emociones y perdonarse mutuamente.

Finalmente, el cuarto nivel consiste en una visión sumamente amplia del problema que se ciñe en aspectos comunitarios y sociales. Es así que durante la mediación son considerados los deseos de grupos sociales que no son parte de la disputa en estricto sentido, pero que de una u otra forma pueden verse afectados. Siguiendo el mismo ejemplo empleado en líneas anteriores, RisKIN sostiene lo siguiente:

41. Traducción libre. Ídem, pp. 20-21. Texto original: "the parties might repair their relationship by learning to forgive one another or by recognizing their connectedness. They might learn to understand themselves better, to give up their anger or desire for revenge, to work for inner peace, or to otherwise improve themselves. They also might learn to live in accord with the teachings or values of a community to which they belong"

42. Traducción libre. Ídem, p. 20. Texto original: “"Level III” mediations focus attention on more personal issues and interests. For example, during the development of the $\$ 30,000$ dispute, each firm's executives might have developed animosities toward or felt insulted by executives from the other firm. This animosity might have produced great anxiety or a loss of self-esteem". 
Por ejemplo, tal vez la ambigüedad en los principios jurídicos pertinentes al caso Computec causó problemas a otras empresas; los participantes pueden entonces considerar opciones para clarificar las leyes, tales como trabajar en conjunto con sus empresas asociadas para promover la promulgación de nuevas normas o crear un modelo de contrato. En otro tipo de disputas las partes pueden enfocarse en mejorar o "transformar" la comunidad ${ }^{43}$.

A través del ejemplo empleado por RISKIN es posible evidenciar que la forma en la que se enfoca el problema (más o menos estrecha) no depende necesariamente del tipo de caso que se trate. De hecho, RISKIN usa el mismo caso (una disputa de US\$ 30.000) para explicar los distintos enfoques que pueden adoptarse. Así, un mediador con una visión sumamente estrecha del problema se centrará exclusivamente en los aspectos legales (interpretar el alcance del contrato, por ejemplo), mientras que un mediador con una visión más amplia se enfocará en la relación comercial entre las partes (nivel II), en llevar a las partes a un proceso de perdón (nivel III), o inclusive en llegar a un acuerdo que reporte un beneficio comunitario (nivel IV). En consecuencia, la amplitud con la que se defina el problema no es una cuestión intrínseca a cada caso, sino que dependerá de lo que cada mediador considere oportuno y eficiente para resolver el tema.

\subsection{Las cuatro orientaciones en la mediación}

Según el estilo del mediador -facilitativo o evaluativo- y la forma en la que aborde el problema -estrecha o amplia- se presentan cuatro distintas orientaciones en la mediación. Resulta fundamental comprender las particularidades de cada una de estas orientaciones, pues tal como lo exponen JEFFREY KRIVIS y BARBARA MCADOO:

43. Traducción libre. Ídem, p. 22. Texto original: "For example, perhaps the ambiguity in legal principles relevant to the Computec case has caused problems for other companies; the participants might consider ways to clarify the law, such as working with their trade associations to promote legislation or to produce a model contract provision. In other kinds of disputes, parties might focus on improving, or "transforming," communities". 
Entender los tipos de estilo del mediador es crucial para mejorar su desempeño. Le permite al mediador seleccionar entre una variedad de técnicas que están a su disposición dependiendo de la naturaleza del caso. Además, facilita explicar a las partes la razón por la que se opta por un determinado acercamiento para la resolución del caso $^{44}$.

Es por esta razón que a continuación se realizará un análisis de las distintas combinaciones: mediador facilitativo con una visión estrecha del problema [3.3.1]; mediador facilitativo con una visión amplia del problema [3.3.2]; mediador evaluativo con una visión estrecha del problema [3.3.3]; y, mediador evaluativo con una visión amplia del problema [3.3.4].

\subsubsection{Mediador facilitativo con una visión estrecha del problema}

El mediador facilitativo con una visión estrecha del problema tiende a formular preguntas a las partes que les permitan alcanzar una perspectiva realista sobre cuál es su situación en el caso de un eventual litigio. Sin embargo, en ningún momento presenta su opinión personal ni tampoco presiona a las partes. Tampoco suele recurrir al análisis de los documentos sustanciales dentro del conflicto (el contrato, por ejemplo). Su principal estrategia radica en comunicarse con las partes a través de la elaboración de preguntas dirigidas al entendimiento de la situación litigiosa y las consecuencias de no alcanzar una solución negociada $^{45}$. Así:

El mediador facilitativo con una visión estrecha del problema comparte la estrategia del narrador evaluativo-estrecho al informar a las partes sobre sus fortalezas y debilidades, así como sobre las consecuencias del no acuerdo. Sin embargo, no da su opinión ni presiona a las partes. A diferencia del me-

44. Traducción libre. J. Krivis y B. McAdoo, “A Style Index for Mediators”. Mediate, «http://www.mediate.com/articles/krivis4.cfm» (05/04/2017). Texto original: "Understanding style is crucial to improving mediator performance. It allows a mediator to select from a spectrum of techniques that might be available depending on the nature of the issues presented. It also makes it simple for the mediator to explain to the disputants why a particular approach might be used in resolving the dispute".

45. Ibídem. 
diador evaluativo, él prefiere evitar el análisis de la documentación relevante ${ }^{46}$.

Las principales estrategias empleadas por un mediador facilitativo-estrecho son las siguientes: (i) hacer preguntas; (ii) ayudar a las partes a identificar sus propios intereses desde una perspectiva legal; (iii) ayudar a las partes a intercambiar propuestas de solución; y, (iv) ayudar a las partes a evaluar dichas propuestas de solución ${ }^{47}$.

En consecuencia, esta orientación se caracteriza principalmente por el uso de preguntas (facilitativo) que estén enfocadas en aspectos legales (estrecho). El mediador se abstiene, entonces, de emitir un criterio o sugerencia sobre el caso y se limita a ayudar a las partes a identificar sus intereses y opciones a través del uso de preguntas.

\subsubsection{El mediador facilitativo con una visión amplia del problema}

Por su parte, el mediador facilitativo con una visión amplia del problema procura evitar que las partes dentro del conflicto se encuadren dentro de sus posiciones. Al contrario, busca que la mediación se realice en torno a los intereses de los involucrados y no de sus posiciones ${ }^{48}$. Este objetivo lo cumple a través de la escucha empática y las preguntas que ayuden a las partes a explorar sus verdaderos intereses, así como a entender los de la otra parte.

Las principales tareas de este tipo de mediador consisten en (i) ayudar a las partes a entender los intereses subyacentes; (ii) asistir a las partes a desarrollar e intercambiar sugerencias de

46. Traducción libre. L. Riskin, N. 38, p. 28. Texto original: "The facilitative-narrow mediator shares the evaluative-narrow mediator's general strategy-to educate the parties about the strengths and weaknesses of their claims and the likely consequences of failing to settle. But he employs different techniques to carry out this strategy. He does not use his own assessments, predictions, or proposals. Nor does he apply pressure. He is less likely than the evaluative-narrow mediator to request or to study relevant documents. Instead, believing that the burden of decision-making should rest with the parties, the facilitative-narrow mediator might engage in any of the following activities".

47. Ibídem.

48. J. Krivis y B. McAdoo, N. 44. 
acuerdo basadas en intereses amplios; (iii) ayudar a las partes a intercambiar propuestas; y, (iv) ayudar a las partes a evaluar dichas propuestas ${ }^{49}$.

$\mathrm{Al}$ igual que en la orientación anterior, este mediador también se abstiene de emitir su criterio y emplea preguntas, pues ésta es una característica propia del estilo facilitativo. Sin embargo, en este caso, las preguntas no se enfocan en aspectos legales, sino que pretenden ayudar a las partes a identificar sus intereses subyacentes, que dependiendo del grado de amplitud con el que el mediador aborde el problema, serán comerciales, personales o comunitarios.

\subsubsection{El mediador evaluativo con una visión estrecha del problema}

En cambio, el mediador evaluativo con una visión estrecha del problema pretende que las partes perciban sus debilidades y fortalezas legales dentro del conflicto. El objetivo principal es que a través de la mediación las partes puedan visualizar cuál es su panorama dentro de un litigio. De este modo se busca que tomen consciencia de las implicaciones de no llegar a un acuerdo negociado $^{50}$.

A diferencia del mediador facilitativo con una visión estrecha del problema, el mediador evaluativo analiza toda la documentación relevante del caso con anterioridad a la mediación ${ }^{51}$. Por otro lado, "la mayoría de las actividades en la mediación se dan en reuniones privadas en las cuales el mediador proporcionará información adicional y empleará técnicas evaluativas" ${ }^{\prime 52}$.

49. Traducción libre. K. RoBerTs, N. 24. p. 195. Texto original: "Four major tasks of the facilitative-broad mediator are: helping parties understand underlying interests, assisting parties in developing and exchanging broad interest-based suggestions for settlement, helping parties exchange proposals, and helping parties evaluate those proposals".

50. L. RisKIN, N. 38, pp. 26-27.

51. Ídem, pp. 26-27.

52. Ídem, p. 27. 
Las principales técnicas evaluativas, presentadas de la menos a la más evaluativa, son las siguientes: (i) evaluar las fortalezas y debilidades del caso de cada lado; (ii) predecir los resultados judiciales; (iii) proponer acuerdos sobre compromisos basados en las posiciones; y, (iv) instar a las partes a resolver o aceptar una propuesta de solución ${ }^{53}$.

En conclusión, se evidencia que el mediador evaluativo adopta una postura más activa en la mediación, pues no se limita a ayudar a que las partes intercambien propuestas de solución, sino que incluso propone acuerdos. No obstante, dado que se trata de un mediador con una visión estrecha del problema, dichos acuerdos se centran exclusivamente en aspectos litigiosos.

\subsubsection{El mediador evaluativo con una visión amplia del problema}

Este tipo de mediador también busca ayudar a las partes a visualizar cuál sería su situación en caso que no logren llegar a un acuerdo. Sin embargo, se enfoca en la posible satisfacción de intereses, en lugar de la posibilidad de ganar o perder en un proceso judicial. Así pues, este mediador predice cómo se podrían satisfacer o no los intereses de las partes en caso de no llegar a un acuerdo. Igualmente, propone fórmulas de solución que cree podría satisfacer los intereses de ambas partes. Así pues, este estilo requiere que el mediador asimile y activamente concilie los intereses de las partes.

Tal como lo establecen JefFrey KRIVIS y BARBARA McAdOO, este estilo de mediador "provee predicciones, evaluaciones y recomendaciones, pero hace hincapié en las opciones que responden a los intereses subyacentes, en lugar de aquellos que se enfocan en generar compromisos exclusivamente sobre intereses estrechos ${ }^{\prime \prime 54}$.

53. Ídem, pp. 27-28.

54. Traducción libre. J. Krivis y B. McAdoo, N. 44. Texto original: "also provides predictions, assessments and recommendations. But she emphasizes options that address underlying interests, rather than those that propose only compromise on narrow issues". 
La principal estrategia de este estilo de mediación es "aprender acerca de las circunstancias y los intereses subyacentes de las partes y otros individuos o grupos afectados, y luego utilizar ese conocimiento para ordenar a las partes hacia un resultado que responda a esos intereses" ${ }^{\prime 55}$. RISKIN explica que para lograr ello el mediador evaluativo-amplio emplea las siguientes técnicas, (ordenadas de la menos a la más evaluativa): (i) entender los intereses subyacentes; (ii) predecir el impacto del no acuerdo sobre los intereses; (iii) desarrollar y ofrecer opciones más amplias; y, (iv) instar a las partes a adoptar la propuesta del mediador o de alguna otra persona ${ }^{56}$.

En efecto, al igual que el mediador evaluativo-estrecho, este mediador asume un rol activo en la mediación en la que está presto a ofrecer opciones de mutuo acuerdo. Estas opciones no se enfocan en aspectos legales, sino que en los intereses de las partes.

Sobre la base de las distintas orientaciones estudiadas se evidencia que no existe un solo tipo de mediador. Al contrario, dependiendo de la orientación que adopte cada mediador existen diferentes técnicas y estrategias, y cada una de estas apuntará a distintos objetivos. Ante ello, y a modo de conclusión, estimamos sumamente útil proporcionar al lector una traducción del cuadro elaborado por LEONARD RISKIN ${ }^{57}$, con el objetivo de que pueda visualizar y sintetizar de mejor manera las cualidades, estrategias y objetivos de los distintos tipos de mediadores:

55. Traducción libre. L. Riskin, N. 38, p. 30. Texto original: “the evaluative-broad mediator's principal strategy es to leran about the circumstances and underlying interests of the parties ant other affected individuals or groups, and the to use that knowledge to direct the parties toward an outcome that responds to such interests".

56. Ibídem.

57. Ídem, p. 35. 


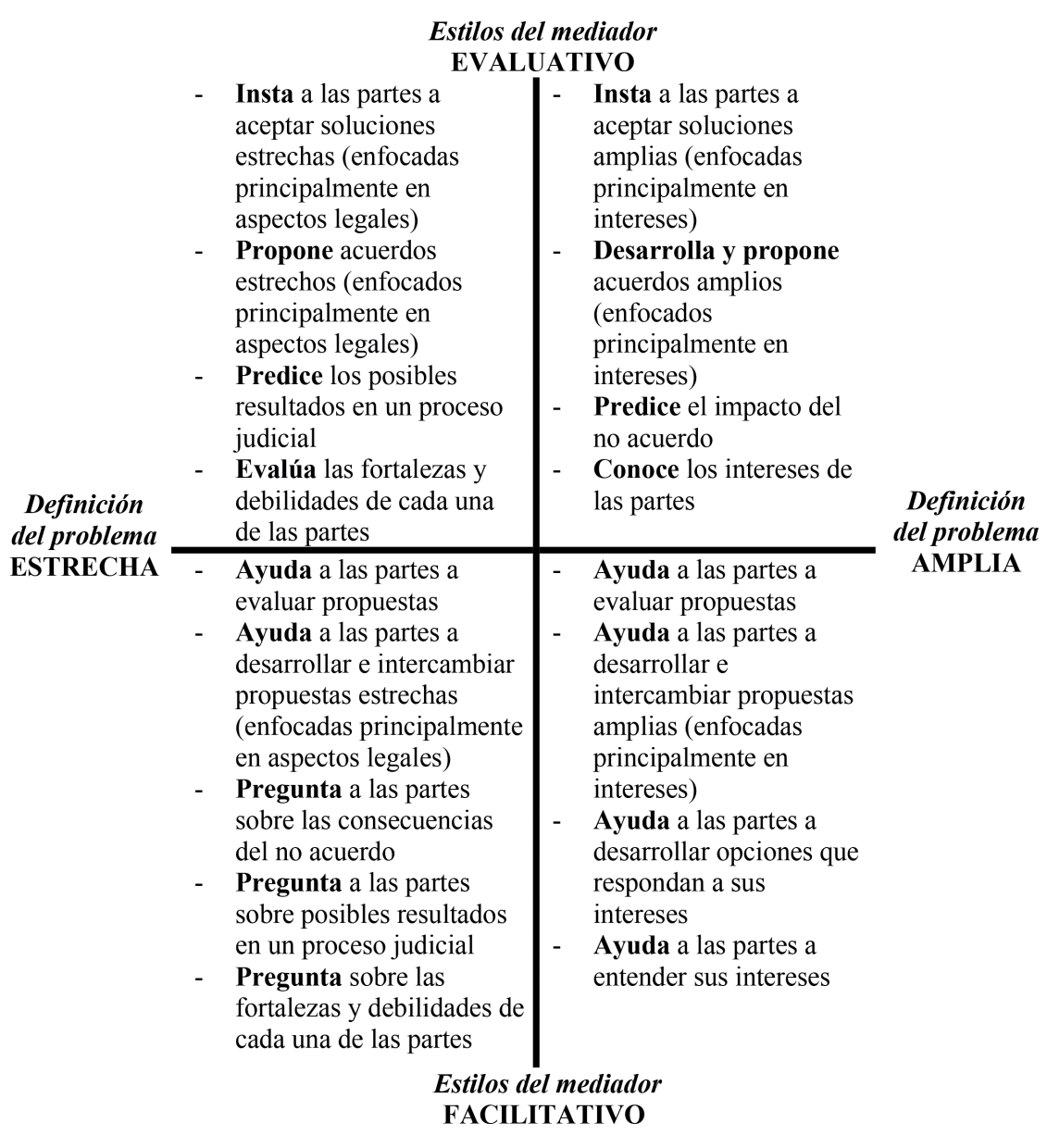

Ilustración 1: Tabla que sintetiza las técnicas empleadas en cada tipo de orientación. La tabla es una traducción de la empleada por L. RISKIN en su artículo "Understanding mediators' orientations, strategies, and techniques: A grid for the perplexed" ( $p$. 35).

\section{4 ¿Se mueven los mediadores en las orientaciones? ¿En qué momento?}

Las orientaciones de la mediación no son estáticas, ni desde el punto de vista del desarrollo de la mediación como práctica, ni tampoco desde lo que hace un mediador en particular en un determinado momento.

La mediación clásica y pura es una mediación facilitativa con una visión amplia del problema. Sin embargo es importante 
tomar en cuenta la evolución histórica ${ }^{58}$ que tuvo este estilo de mediación en Estados Unidos: uno de los países referentes en mediación. Así, en este país, a lo largo de los años de práctica la mediación se ha convertido en evaluativa con una visión estrecha ${ }^{59}$. Esta evolución revela la posibilidad (y factibilidad) de cambio en la orientación del mediador.

En su práctica general, cada mediador tiende a alinearse a una de las orientaciones expuestas anteriormente, sin embargo su orientación nunca es estática. El mediador no necesariamente se apega a una orientación determinada para todos los procedimientos, y ni siquiera utiliza una sola orientación en todas las etapas dentro de un mismo procedimiento. Las diferentes orientaciones se acoplan a los distintos casos, dependiendo de los puntos contenciosos, las relaciones entre las partes, los objetivos futuros de las mismas, etc. Así mismo, cada una de las orientaciones puede resultar más o menos propicia en cada una de las etapas del procedimiento.

Los estilos del mediador constituyen un espectro por donde los mediadores fluctúan, y no necesariamente son polos opuestos. ANDREW P. WYCKOFF explica que este espectro entre los polos facilitativo-evaluativo constituye una gran escala de grises, en el cual los estilos suelen ser difíciles de distinguir. Desde una perspectiva evaluativa, el mediador evalúa los hechos y los potenciales resultados, para así ofrecer posibles soluciones a la controversia. Desde una perspectiva facilitativa, el mediador ayuda a las partes a que estas evalúen los hechos y los potenciales

58. En un inicio (1970-1980), la mediación en Estados Unidos giró en torno a intereses comunitarios, de hecho se crearon varios centros de mediación comunitaria. Del mismo modo, durante esa época en dichos centros se desarrollaron programas para la resolución de disputas vecinales. Dada la naturaleza de estos conflictos, la mediación se caracterizó por una orientación facilitativa-amplia. Sin embargo, con el tiempo surgieron algunos servicios legales que ofrecían mediación para resolver casos en los que ninguna de las partes podría pagar los gastos de un abogado58. . A su vez, los empresarios también empezaron a optar por este servicio. Si bien ellos tenían dinero para cubrir los honorarios de los abogados, el costo que generaba la demora del proceso judicial era inviable. Es por ello que optaron por la mediación. Es así que poco a poco se dio paso a los estilos evaluativos, ya que las exigencias del caso requerían del mediador mayor asesoramiento en la disputa. Véase, K. KovACH, The Evolution of Mediation in the United States: Issues Ripe for Regulation May Shape the Future of Practice, p. 390. Citado por N. ALEXANDER, "Global Trends in Mediation", Kluwer Law International, 2006 y J. FolBERG, "Development of Mediation Practice in the United States". Iuris Dictio, No. 14, 2015, p. 36.

59. Véase, K. Kovach, N. 58 y J. FolberG, N. 58. 
resultados, para así generar decisiones consensuales ${ }^{60}$. Entre estas dos perspectivas, se abre la posibilidad de una serie de combinaciones de actitudes y posturas que puede asumir el mediador. Igualmente, el mediador puede tener una visión estrecha de la controversia, manejando una negociación eminentemente distributiva y sin embargo incorporar un elemento que dé cierta amplitud al problema, como el acuerdo de confidencialidad.

La orientación del mediador muchas veces se relaciona con la actitud que tienen las partes. Un mediador tiende a ser evaluativo cuando nota que las partes quieren y desean que se les provea de consejos y guías acerca de las mejores alternativas para solucionar en conflicto. De igual manera, lo hace cuando las partes confían en que el mediador está cualificado para brindar dicha guía en virtud de su entrenamiento, experiencia, objetividad, etc. ${ }^{61}$. Por el contrario, un mediador tiende a ser facilitativo cuando las partes parecen estar dispuestas y en capacidad de trabajar con sus contrapartes, y cuando estas pueden indudablemente entender su situación de mejor manera que el mediador y sus propios abogados ${ }^{62}$. Igualmente tiende a reaccionar a la definición del problema que presenten las partes y/o sus abogados.

Así también, la etapa del procedimiento de mediación es un factor fundamental en el estilo que adoptará el mediador. "Los estilos del mediador frecuentemente evolucionan a lo largo del proceso de negociación, comenzando por el facilitativo y avanzando hacia el evaluativo" ${ }^{\prime \prime}$. El enfoque evaluativo implica una participación mayor por parte del mediador, quien interviene para evaluar la situación del procedimiento. Dicha intervención puede no ser deseada por las partes al inicio de un procedimiento de mediación; en etapas en las cuales las partes no han desarrollado una plena confianza en el mediador, y por tanto, desconocen la legitimidad del mismo para brindar su opinión. Es por esto

\footnotetext{
60. А. P. WyскоғF. "An Investigation into the "facilitative-evaluative" debate regarding mediator styles", Scholar Works at University of Montana, 2000, p. 6.

61. L. Riskin, N. 38, p. 19.

62. Ibídem.

63. D. DeVRIES, Mediation: Understanding Facilitative, Evaluative and Directive Approaches, «http://www.dkdresolution.com/articles/Mediation.Understanding.3.1.pdf» (07/11/16).
} 
que el timing o la determinación del momento apropiado para utilizar el estilo evaluativo es importante; instar a las partes a llegar a un acuerdo con frecuencia se vuelve necesario, y hacerlo resulta más efectivo una vez establecida una relación de confianza ${ }^{64}$. El mediador MiCHAEL ROBERTS concuerda con esto, y afirma que

[E]n etapas tempranas de una mediación, suelo utilizar un enfoque facilitativo para ayudar a las partes a trabajar en el problema por su cuenta y alcanzar sus propias conclusiones. Las técnicas evaluativas se reservan para las etapas más avanzadas de la mediación, cuando una relación de confianza se ha establecido entre las partes y el mediador. En ese momento la opinión del mediador sobre la validez de las posiciones de las partes y las sugerencias para la solución de la controversia son más propensas a ser aceptadas. La mayoría de mediadores experimentados no dudan en evaluar la validez de las posiciones de las partes y ofrecer sugerencias de posibles soluciones en el momento apropiado. De hecho, la mayoría de las partes lo esperan. La habilidad está en saber cómo y cuándo usar ambos enfoques ${ }^{65}$.

\section{Revisión de estilos y definición del problema en la me- diación en la ciudad de Quito}

La presente investigación intenta encontrar los estilos que adoptan los mediadores de la ciudad de Quito, así como la definición del problema que emplean para su trabajo. Igualmente busca encontrar las expectativas que sobre estos aspectos tienen los abogados que acuden a mediación en la misma ciudad.

64. Ibídem.

65. Traducción libre. M. RoBERTs, Choosing The Right Mediator: A Guide to Effective Mediation Styles, «http://www.mediate.com/articles/roberts3.cfm» (07/11/16). Texto original: "In the early stages of a mediation, I tend to use a facilitative approach to help the parties work through the issues on their own and reach their own conclusions. Evaluative techniques are reserved until the later stages of the mediation when a rapport has been established between the mediator and the party. At this point the mediator's opinions as to the validity of a party's position and suggestions for settlement are more likely to be accepted. Most experienced mediators do not hesitate to evaluate the validity of a party's position and offer suggestions for settlement at the appropriate time. Indeed, most parties expect it. The skill is in the knowing how and when to use both approaches". 
En la presente sección se exponen los resultados de una investigación cuantitativa realizada a través de encuestas, con la finalidad de identificar la aplicación de las orientaciones en la práctica de la mediación.

\subsection{Metodología de investigación}

A fin de identificar los estilos adoptados por los mediadores y preferidos por los abogados, así como el enfoque con el cual se define el problema, la presente investigación realizó encuestas a mediadores y abogados (por separado) de la ciudad de Quito. La investigación llevada a cabo replicó la metodología usada por JEFFREY KRIVIS y BARBARA McAdOO en "A Style Index for Mediators" 66 .

La encuesta consistió en 31 afirmaciones a las cuales los mediadores y abogados encuestados debían asignar un puntaje entre el 1 y el 10, siendo el 1 "completamente en desacuerdo", y el 10 "completamente de acuerdo". 12 de las preguntas apuntaban a determinar el estilo del mediador, y 15 apuntaban a identificar la amplitud con la que definen problema. Las 4 preguntas restantes se referían a técnicas procedimentales independientes.

Las encuestas fueron enviadas a mediadores y abogados de una gran variedad de centros de mediación en la ciudad de Quito. La finalidad de involucrar en el estudio tanto a abogados como a mediadores es comparar sus orientaciones y determinar si aquello que los mediadores ofrecen es, efectivamente, lo que los abogados esperan de los procedimientos de mediación a los que asisten acompañando a las partes. Participaron en ella 35 mediadores de distintos centros de la ciudad y 54 abogados usuarios de dichos centros. Entre los mediadores encuestados, se incluye la respuesta institucional presentada por el Centro Nacional de Mediación de la Función Judicial (CNMFJ), misma que motiva cada una de las afirmaciones (por este motivo, los mediadores del CNMFJ no respondieron individualmente las encuestas).

66. J. Krivis y B. McAdoo, N. 44. 
Por el tamaño de la muestra evaluada, los resultados de este estudio inicial son meramente ejemplificativos y representan las preferencias de los abogados y mediadores que respondieron la encuesta, exclusivamente. No obstante, nos permiten obtener luces de las preferencias y tendencias más generales.

Al momento de contestar la encuesta, otorgar un puntaje alto a las afirmaciones sobre estilo implica que el abogado o mediador prefiere un estilo evaluativo, mientras que asignar un puntaje bajo refleja su inclinación hacia el estilo facilitativo. De manera similar, otorgar un puntaje alto a las afirmaciones sobre definición del problema implicaba preferir una visión amplia del problema, mientras que asignar un puntaje bajo refleja la preferencia por una visión estrecha. Por motivos didácticos, algunas preguntas se encontraban invertidas a fin de que los participantes no logren identificar la postura que representaba el asignar puntajes altos o bajos y que respondan con la mayor objetividad posible. En estos casos los puntajes fueron nuevamente invertidos para computar correctamente la evaluación de los resultados finales.

Los resultados obtenidos se exponen de dos maneras principales. Los estilos y la definición del problema se exponen a través de gráficos de barras comparativas que analizan las respuestas de abogados y mediadores a las preguntas más relevantes (secciones $4.2,4.3$ y 4.5). Así, se pueden observar los puntajes asignados con mayor frecuencia por abogados y mediadores en cada una de las preguntas, y comparar sus preferencias con respecto a temas específicos de la mediación. En ambos casos, se exponen los resultados sobre 5 puntos y no sobre 10 para visibilizar con mayor claridad la tendencia existente.

Finalmente, las orientaciones de la mediación se reflejan en una gráfica de cuadrantes (sección 4.4) en la cual se ubica a cada abogado y mediador participante en un punto específico del cuadrante. Esto refleja sus preferencias acerca del estilo de la mediación y la definición del problema. La ubicación en la que cada abogado o mediador se encuentra es determinada a través de la obtención de un promedio de las calificaciones dadas a todas las 
preguntas de la encuesta. Igualmente los resultados se exponen sobre 5 puntos para visibilizar con mayor claridad la tendencia existente.

\subsection{Estilos de mediación en la ciudad de Quito}

Conforme los resultados de las preguntas que se verán más adelante, la mayoría de los mediadores encuestados reflejan un estilo evaluativo. Se diferencia de esta regla el CNMFJ, quién en su respuesta institucional aboga por un estilo facilitativo de mediación.

La mayoría de los abogados encuestados optó también por un estilo evaluativo del mediador.

A continuación revisaremos los resultados a las preguntas más relevantes que sustentan esta conclusión:

\section{- Emitir criterios jurídicos}

Respecto a la posibilidad de que los mediadores proporcionen su criterio jurídico a fin de ayudar a las partes a entender las fortalezas y debilidades de sus posiciones legales, el $40 \%$ de los mediadores se manifestaron a favor y el $31,43 \%$, en contra; mientras que los abogados demostraron una tendencia mucho más definida manifestándose el $57,41 \%$ a favor y solamente el $18,51 \%$ en contra. 


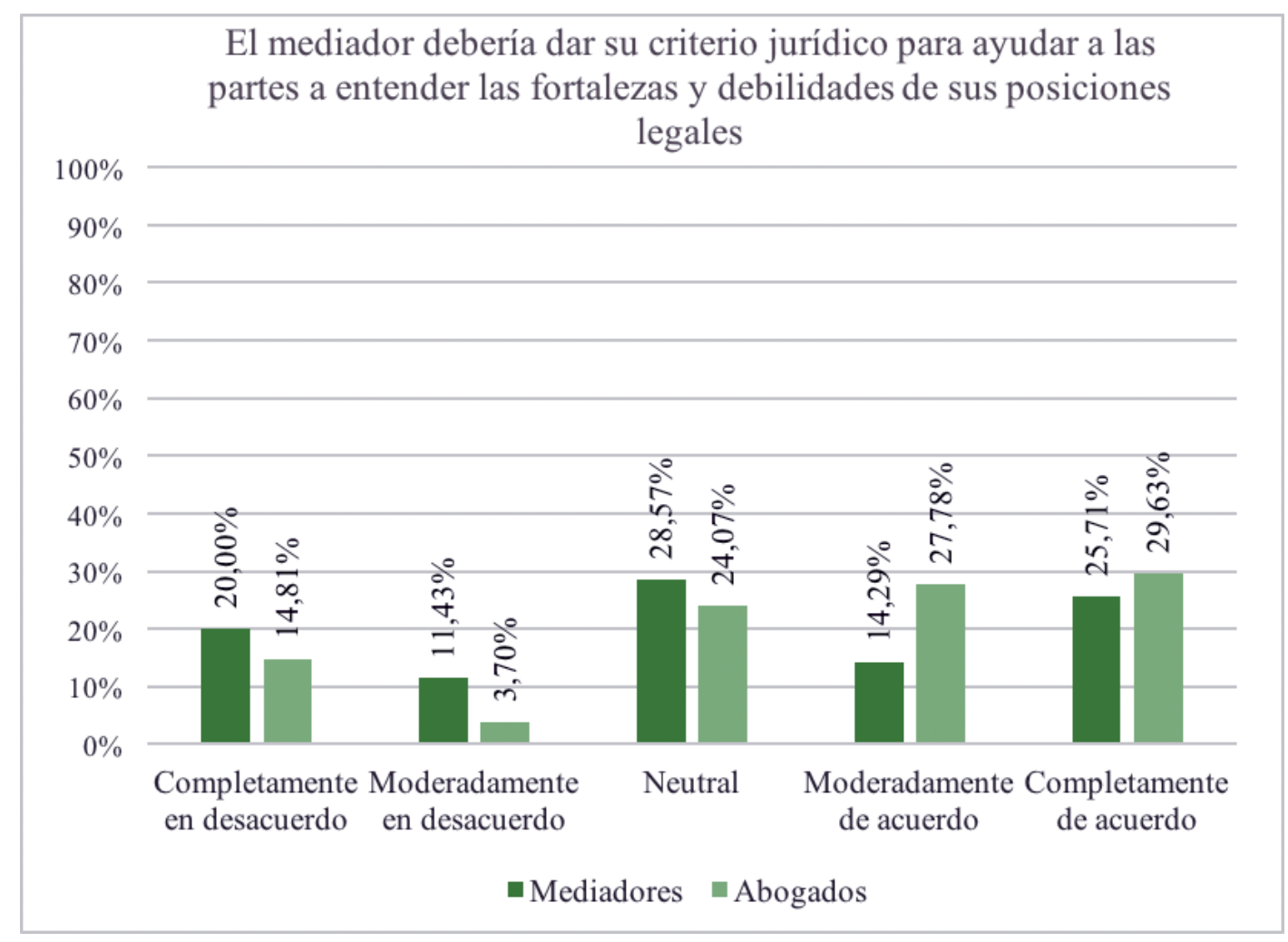

Ilustración 2: Gráfico comparativo de barras de las respuestas de los mediadores y abogados a la pregunta "El mediador debería dar su criterio jurídico para ayudar a las partes a entender las fortalezas y debilidades de sus posiciones legales".

Las respuestas de mediadores a esta pregunta revelan que no hay una tendencia clara, existe un porcentaje similar entre quienes están de acuerdo y quienes están en desacuerdo con dar su opinión jurídica. De hecho, el 28,57\% de los mediadores no tienen una postura clara al respecto, lo que implica un porcentaje mayor a los que están completamente de acuerdo o completamente en desacuerdo.

Por su parte, el CNMFJ se inclina a un estilo facilitativo, pues respondió que está completamente en desacuerdo, motivándolo de la siguiente manera:

La manifestación de un criterio jurídico, es muy cercano a la opinión, lo que es tarea de un asesor legal o del informe que pudiera realizar un perito, especialista en la materia. Esta no es tarea del mediador o mediadora, por lo que, siempre ma- 
nifiesta a las partes el derecho de acudir a la asesoría legal que les brinda el Estado, a través de la Defensoría Pública; o, privada, según las posibilidades con que cuente el usuario o usuaria, este es un recurso que corre por cuenta de ellos.

Es decir que, la tarea de ayuda a las partes para que entiendan las fortalezas y debilidades de sus posiciones legales, es una tarea de asesoría jurídica que está en contradicción con la función de imparcialidad y neutralidad del mediador o mediadora. Ahora bien, desde el enfoque de garantía de derechos al que un servidor público que presta un servicio de administración de justicia, como es la mediación, está sujeto por mandato constitucional, al respeto y garantía de los derechos de todos los usuarios y usuarias; así como a la aplicación directa de principios, que permitan la plena vigencia de los derechos de los usuarios o usuarias.

Por lo tanto, se debe diferenciar que el deber de informar a los usuarios o usuarias del goce de sus derechos y del deber de cumplir con obligaciones, es opuesto a la opinión jurídica que resulta de una consulta, lo que es tarea de un asesor o asesora legal.

Respecto a los abogados existe una tendencia mucho más definida hacia un estilo evaluativo, en donde la mayoría de abogados que concurren a la mediación en compañía de las partes buscan que el mediador emita su criterio para ayudar a evaluar las debilidades y fortalezas del caso.

Es interesante reconocer la diferencia que existe entre mediadores y abogados, pues mientras los últimos buscarán un criterio jurídico, solamente una fracción de los mediadores estarán dispuestos a atender tales expectativas. Esto nos invita a cuestionarnos si convendría que en el futuro los mediadores se inclinen por un estilo más evaluativo, o si se deberían desarrollar nuevos métodos de solución de controversias que ofrezcan una evaluación neutral anticipada, como el ENA $^{67}$, el mini trial ${ }^{68}$ o el juez de alquiler ${ }^{69}$.

67. La evaluación neutral anticipada (ENA) consiste en un método en el que las partes acuden ante un tercero neutral para que evalúe las posiciones, debilidades y fortalezas de cada parte y sobre la base de ellas determine si están lo suficientemente cerca como para sentarse a la mesa de negociación. Para mayor información sobre ENA véase, L. VADO, "Medios alternativos de resolución de conflictos", p. 387, «http://www.cejamericas.org/Documentos/DocumentosIDRC/7nuevo.pdf» (21/06/2017) у M. IzUZQUIZA, “El conflicto: diversos sistemas de resolución”. Cartapacio de Derecho, pp. 10-11. 
Ximena Bustamante, María Bernarda Carpio Frixone, Isabela Moreno E María Gracia Naranjo Ponce

\section{- Predecir el posible resultado en el proceso judicial}

Sobre la conveniencia de que el mediador se pronuncie acerca del posible resultado del conflicto si este fuese llevado a las cortes, el $68,57 \%$ de los mediadores se pronunció favorablemente mientras que solamente el $11,42 \%$ estuvo en contra. Igualmente, el $50 \%$ de los abogados se pronunció a favor mientras que el $29,63 \%$ estuvo en contra.

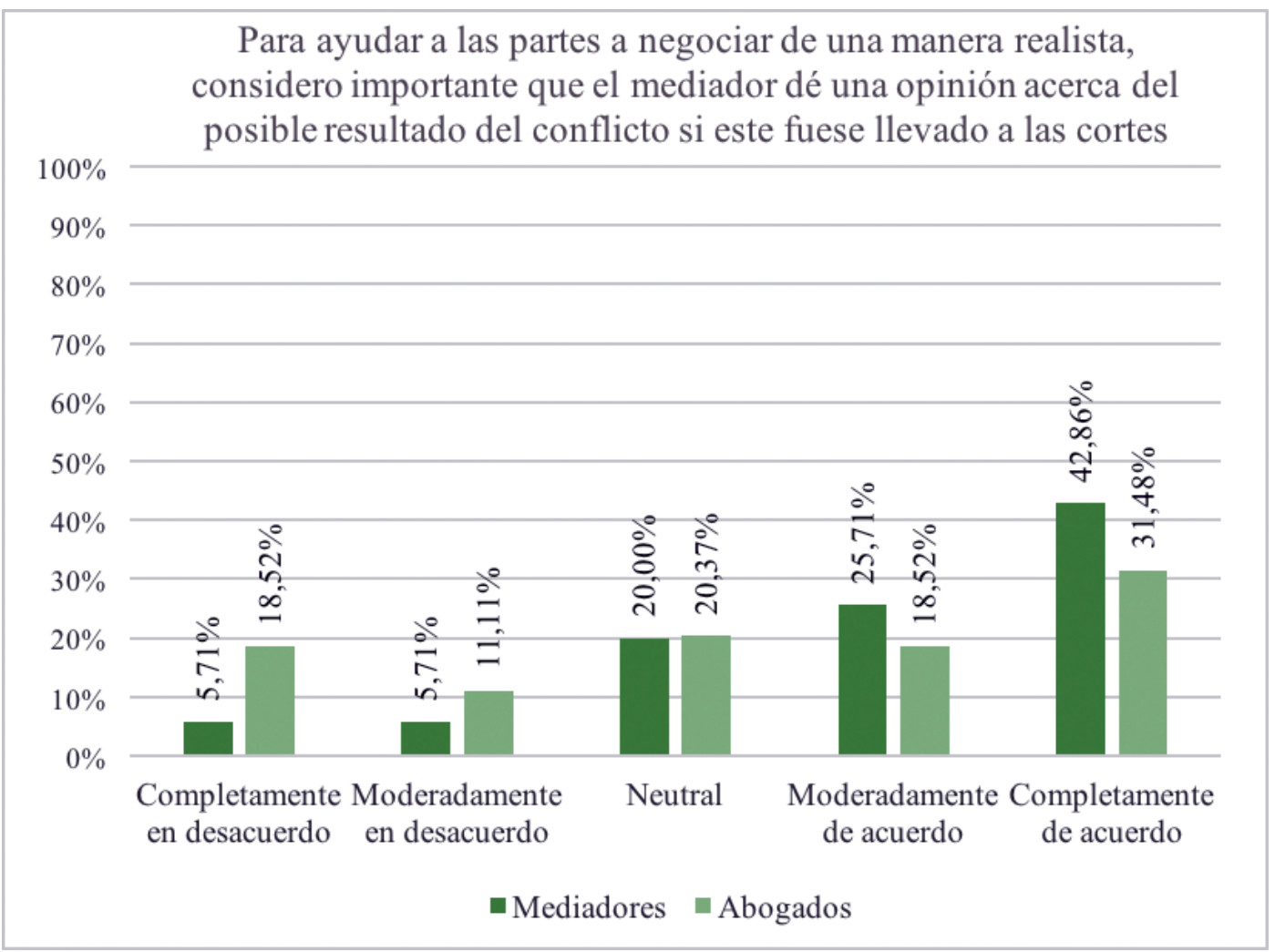

Ilustración 3: Gráfico comparativo de barras de las respuestas de los mediadores y abogados a la pregunta "Para ayudar a las partes a negociar de una manera realista considero importante que el mediador dé una opinión acerca del posible resultado del conflicto si este fuese llevado a las cortes".

68. El mini trial es un método alternativo a la resolución de disputas que consiste en una suerte de moot court en el que un tercero brinda asesoría a las partes y les señala qué es lo que cada una tiene para perder o ganar un eventual juicio. Las decisiones de este tercero pueden ser vinculantes dependiendo de la legislación. Para mayor información sobre este mecanismo véase, J. DAVIS y L. OMLIE, "MiniTrials: The Courtroom in the Boardroom", Willamette Law Review, Vol. 21, 1985.

69. Por su parte, el juez de alquiler (rent a judge) es un proceso en el que interviene un juez retirado y con prestigio por su idoneidad y su imparcialidad. Este juez emite un dictamen que si bien no es vinculante es valorizado por las partes dado su prestigio. Para mayor información sobre este mecanismo véase, K. Stone, Alternative Dispute Resolution, University of California, 2004, pp. 2-3. 
Los mediadores consideran útil y apropiado el anticipar los posibles resultados del caso en la corte. Tal vez esto se relaciona con el rol del mediador como agente de la realidad, lo que les permite a las partes reevaluar sus posiciones. Por su parte, el CNMFJ tuvo una posición neutral aunque reconoció valor a esta técnica de la siguiente manera: "conforme la aplicación del método lineal de negociación, dependiendo del nivel del conflicto, se motiva el análisis de la Mejor Alternativa a un Acuerdo Negociado (MAAN)".

Los abogados no reflejaron una tendencia tan clara. El 50\% mostró una tendencia favorable, un $20,37 \%$ una postura neutral y el $29,63 \%$ se pronunció en contra. A pesar de que la mayoría de abogados se agrupa hacia el estilo evaluativo, con estos resultados parecería que los abogados no confían tanto en la predicción que pudiera realizar el mediador. Es interesante comparar las respuestas a esta pregunta con las de la pregunta anterior. Mientras que los abogados buscan del mediador un criterio jurídico para evaluar las debilidades de su caso, parecerían no tan entusiastas con la idea de que el mediador anticipe el posible resultado en la corte.

\section{- Realizar propuestas de acuerdo}

El 51,85\% de los abogados encuestados está completamente de acuerdo en que el mediador proponga opciones de solución que satisfagan los intereses de las partes; mientras que el 28,57\% de los mediadores considera lo mismo. El 12,96\% de los abogados y el $31,43 \%$ de mediadores no tienen una tendencia clara; mientras que el 3,7\% de abogados y el 8,57\% de los mediadores están completamente en desacuerdo. A pesar de la dispersión en estos resultados podemos evidenciar que existe una tendencia favorable hacia la propuesta de opciones de solución por parte del mediador. 


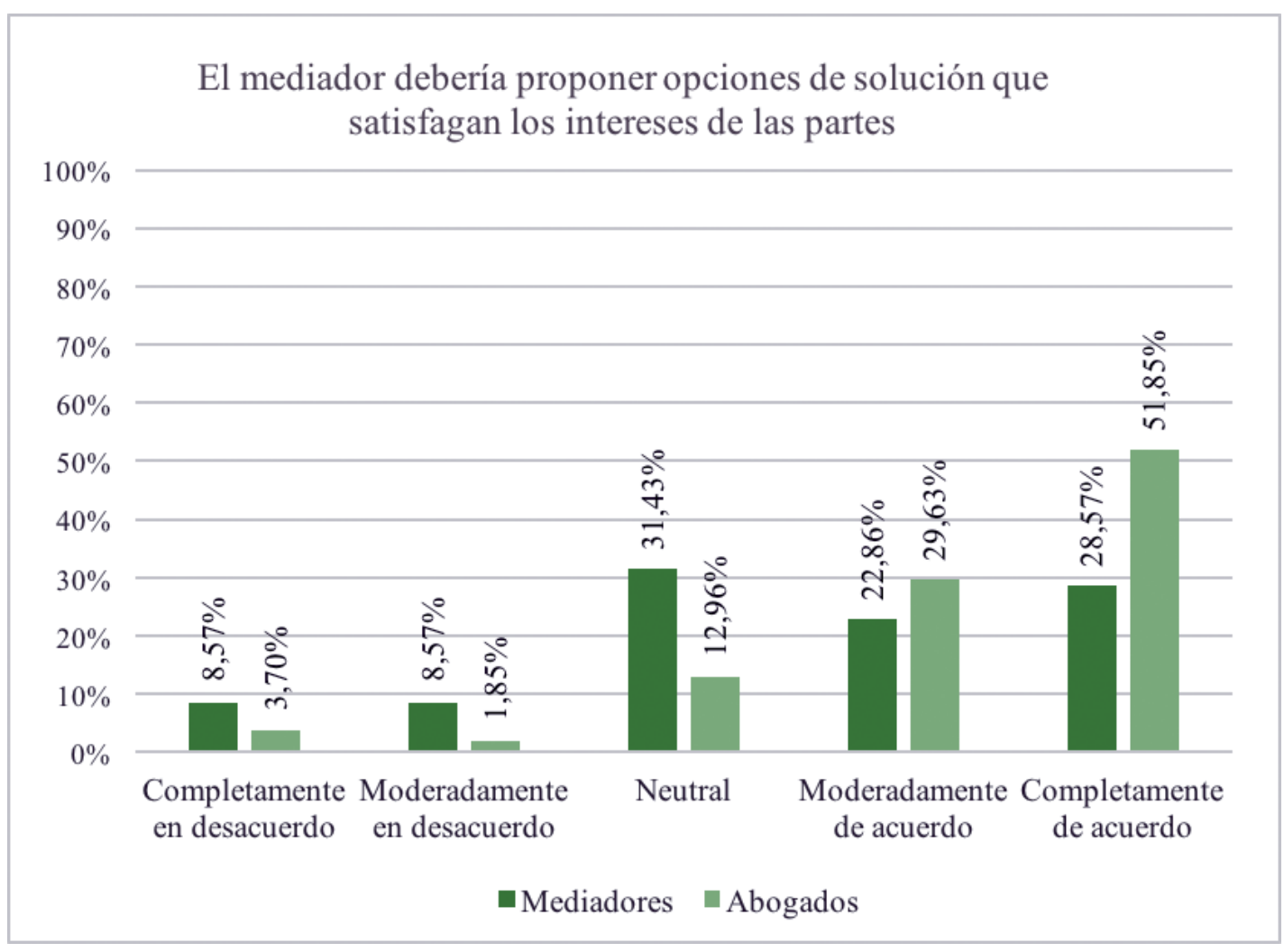

Ilustración 4: Gráfico comparativo de barras de las respuestas de los mediadores y abogados a la pregunta "El mediador debería proponer opciones de solución que satisfagan los intereses de las partes".

Si bien respecto a los mediadores los resultados se encuentran más dispersos que en las respuestas de abogados, en ambos casos podemos constatar una tendencia evaluativa. Sin embargo, es importante notar que los abogados están más de acuerdo con que el mediador realice fórmulas de acuerdo, que los mismos mediadores. De hecho, en las respuestas de mediadores el 31,43\% no revela tendencia alguna, mientras que en abogados este valor es de tan solo $12,96 \%$.

De igual manera, el porcentaje de abogados que está completamente de acuerdo con que los mediadores propongan opciones en el procedimiento supera el $50 \%$, mientras que en los mediadores esta cifra es tan solo del $28,57 \%$. Esto nos lleva a cuestionarnos cómo se desarrollará en el futuro la práctica de la mediación. Tal vez los abogados buscarán mediadores que propongan fórmulas de solución; o tal vez los mediadores irán adoptando esta técnica 
en su práctica con mayor regularidad; probablemente reflejando la adopción cada vez mayor de un estilo evaluativo, como sucedió en los Estados Unidos.

Es importante resaltar la posición del CNMFJ, quien señaló que está completamente en desacuerdo sobre la posibilidad de que los mediadores propongan opciones de solución, fundamentando tal decisión de la siguiente forma:

[E]l mediador o mediadora, no sugiere o propone opciones de solución, sino que ayuda a que las partes identifiquen la mejor solución con la que estarían dispuestas para llegar a un acuerdo. Existe una sutil diferencia entre proponer o sugerir; $\mathrm{y}$, ayudar a que salga de las mismas partes, la mejor solución al conflicto. Lo primero, quita neutralidad o imparcialidad, al mediador o mediadora, ya que es una exteriorización de cómo le parece mejor resolver el conflicto; mientras que, lo segundo, es fruto de la aplicación de las herramientas de comunicación y de la tarea de empoderamiento que es un eje transversal al trabajo del mediador o mediadora.

Esta respuesta denota una tendencia claramente facilitativa, pues se advierte que sugerir opciones de acuerdo contraviene la neutralidad e imparcialidad del mediador. Esta preocupación es propia de los mediadores comprometidos con un estilo facilitativo.

\section{- Especialización del mediador}

Sobre la necesidad de que los mediadores sean especializados, el $65,71 \%$ de los mediadores está completamente de acuerdo y ninguno de ellos está completamente en desacuerdo. En cuanto a los abogados, el 48,15\% está completamente de acuerdo, mientras que el 3,7\% está completamente en desacuerdo. 


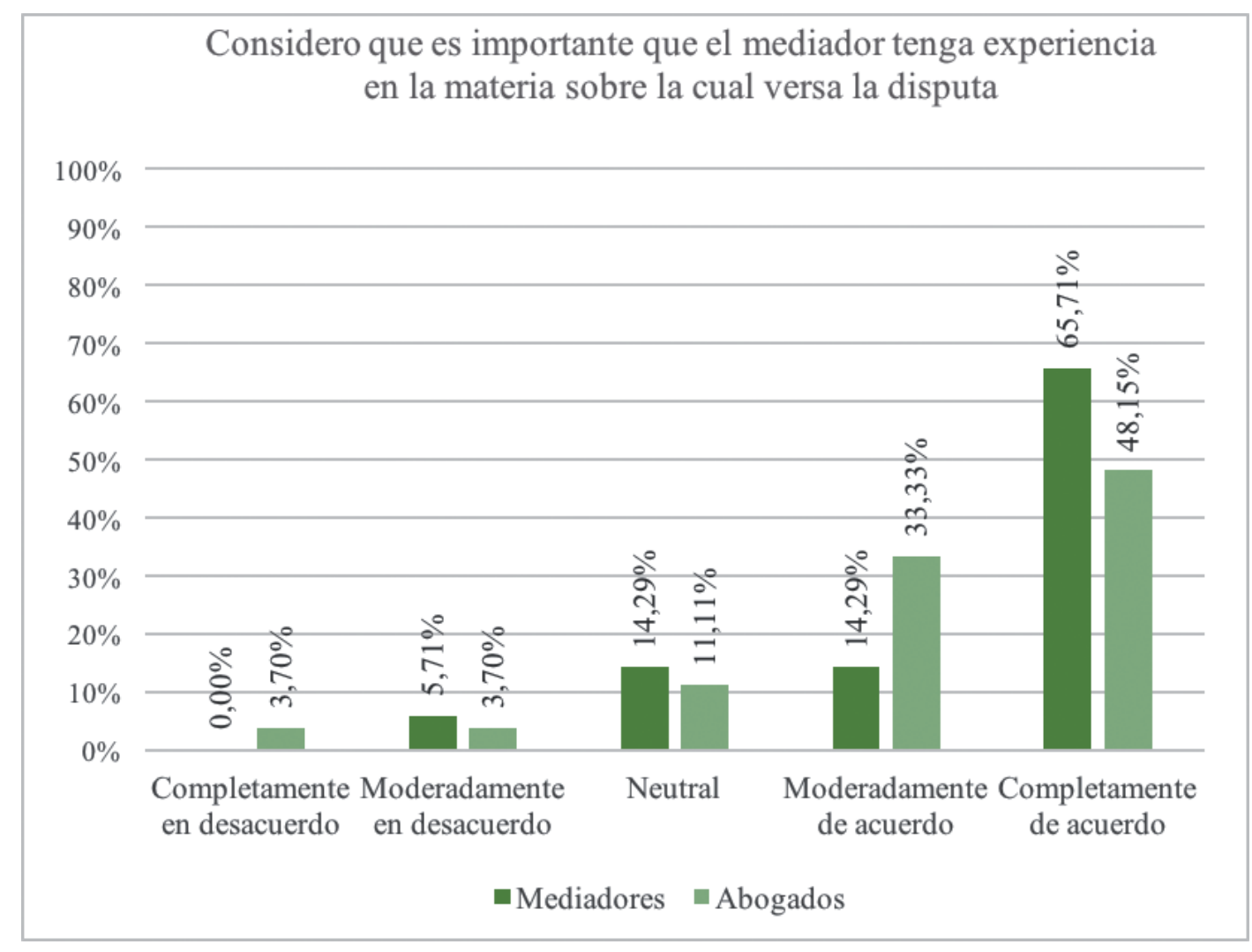

Ilustración 5: Gráfico comparativo de barras de las respuestas de los mediadores y abogados a la pregunta "Considero que es importante que el mediador tenga experiencia en la materia sobre la cual versa la disputa".

El estilo evaluativo de mediación implica que los mediadores conozcan de la materia que están mediando; de este modo podrán brindar un mejor criterio jurídico, realizar predicciones más precisas, o presentar propuestas de solución plausibles. En cambio, un estilo facilitativo no requiere especialización en la materia, sino más bien el adecuado uso de técnicas y estrategias de comunicación y negociación. Las respuestas a esta pregunta confirman que la mayoría de encuestados, tanto mediadores como abogados dan importancia a la especialización del mediador, característica que es fundamental en cualquier orientación evaluativa. Igualmente, el CNMFJ respondió que está moderadamente de acuerdo, tomando en cuenta que:

Es necesario que el mediador cuente con un nivel de conocimiento y experiencia adecuados para el ejercicio de sus fun- 
ciones. Al momento de la atención de un caso, el estudio o análisis de los elementos del conflicto, podría tener inquietudes, lo que le permitirá identificar la necesidad de apoyo técnico, para fortalecer sus capacidades con la debida antelación a la audiencia de mediación.

\section{- Acceso a las posturas legales antes de la mediación}

Finalmente, se preguntó a los encuestados acerca de la conveniencia de que el mediador tenga escritos con anterioridad en los que las partes expliquen su postura legal. Al respecto, el 28,57\% de los mediadores se pronunció a favor. En cambio, el 45,71\% se manifestó en contra. Al inverso, el 53,7\% de los abogados está de acuerdo en que se presente escritos con anterioridad, mientras que el $20,37 \%$ está en contra.

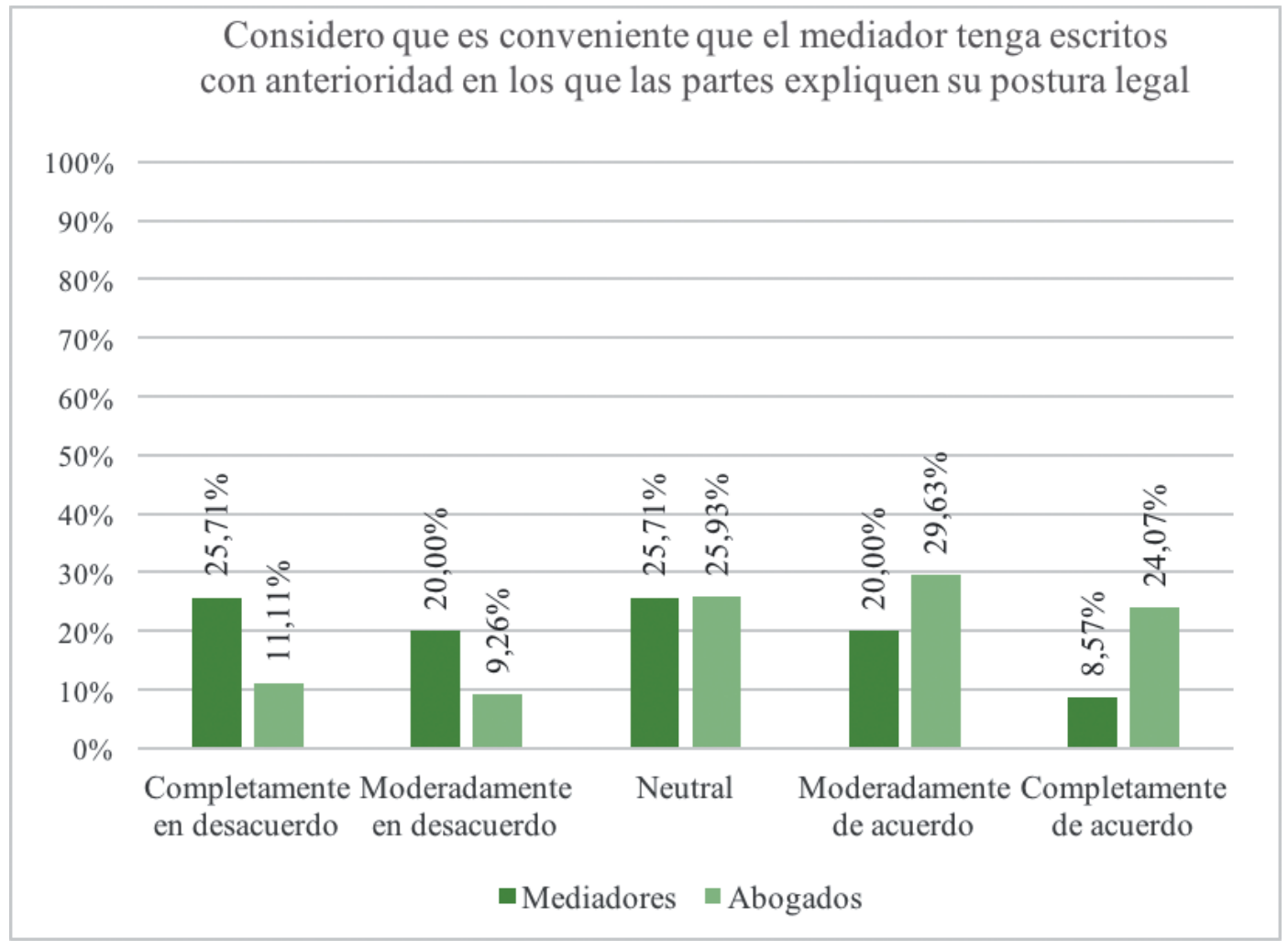

Ilustración 6: Gráfico comparativo de barras de las respuestas de los mediadores y abogados a la pregunta "Considero que es conveniente que el mediador tenga escritos con anterioridad en los que las partes expliquen su postura legal". 
Esta pregunta nos permite obtener luces sobre si existe o no una inclinación de los abogados y mediadores a favor de la premediación ${ }^{70}$. Conocer acerca de los documentos o reportes técnicos con anticipación para determinar cómo manejar el caso trae consigo variadas reacciones entre los encuestados. El poder decidir por cómo se manejará el caso implica un tema de estructura y estrategia, no un tema de toma de decisiones o posiciones de manera anticipada.

Se puede evidenciar que en el caso de los mediadores, a pesar de existir resultados dispersos -en particular porque el 25,71\% de los encuestados no tienen preferencia alguna- sí existe una tendencia desfavorable frente a la posibilidad de contar con documentos previos y revisarlos a manera de preparación de una mediación. Esto refleja una visión un poco más facilitativa de parte de los mediadores, quienes tal vez se imaginan que es mejor que las partes no tengan posiciones definidas que impidan la exploración de intereses. Igualmente, nos permite evidenciar que los mediadores no le dedicarían mucho tiempo y esfuerzo a la premediación.

De hecho, el CNMFJ sostuvo que: "no es conveniente que el mediador tenga escritos con anterioridad en los que las partes expliquen su postura legal. Si bien, las partes podrían presentarlos, nada impide que los reciba, sin embargo, la audiencia de mediación es el espacio previsto para que puedan manifestar sus criterios e intereses".

Por su parte, los abogados preferirían que los mediadores lleguen preparados a la audiencia revisando los documentos legales. Es interesante notar la discordancia en este punto, en que no se correlacionan los prestadores del servicio con los usuarios del mismo. Por lo que es probable que los documentos elaborados

70. La premediación implica tanto la preparación del cliente con su abogado antes de la mediación, como la preparación anticipada que realiza el mediador del caso y de la estrategia que utilizará durante la audiencia. A medida que la imagen esté más completa a los ojos del mediador, más fácil se hace la dirección del procedimiento a una solución. Véase, M. SHER, The High Cost of Failing to Prepare for Mediation, «https://www.mediate.com/articles/SherM5.cfm» (05/04/2017) y C. HILL, Achieving the Promise of Mediation, «https://www.mediate.com/articles/HillC3.cfm» (05/04/2017). 
por los abogados, con el afán de exponer al mediador su perspectiva sobre el caso, pueden ser en muchas ocasiones ignorados.

Estos resultados son un llamado de atención para otorgar mayor importancia a los escritos preparados por las partes y darle valor a la fase de premediación.

Sobre la base del análisis realizado es posible concluir que existe una tendencia general hacia un estilo evaluativo, tal como se desprende del cuadro expuesto en la sección 4.4 que se verá más adelante.

Los mediadores reflejan una tendencia evaluativa aunque no absolutamente, mientras que los abogados expresan una clara preferencia por un estilo más evaluativo. Por su parte, el CNMFJ evidencia un estilo de mediación facilitativo, comprometido con la pureza de la mediación clásica.

Por otro lado, es importante resaltar que existen ciertos temas en los cuales no existe armonía entre lo que quisieran los abogados y lo que ofrecen los mediadores. Esta situación nos invita a imaginarnos cómo se desarrollará la mediación en el futuro y las técnicas que adoptarán los mediadores en su ejercicio profesional a fin de atender las necesidades, expectativas y preferencias de los usuarios. Igualmente, quedan temas latentes como la necesidad de dar mayor énfasis a la fase de premediación y la tendencia a una mayor especialización de la profesión.

\subsection{Definición del problema en la ciudad de Quito}

En cuanto a la definición del problema a abordar, esta investigación no llegó a resultados concluyentes. Parecería que tanto mediadores como abogados se adaptan a la definición del problema que resulte más conveniente en cada caso.

A continuación revisaremos los resultados a las preguntas más relevantes que sustentan esta conclusión: 


\section{- Enfoque en las cuestiones jurídicas}

Una gran cantidad de mediadores y abogados considera que el rol del mediador es el de ayudar a las partes a entender y llegar a una solución sobre las cuestiones jurídicas del caso. El 71,43\% de mediadores y el 55,55\% de abogados muestran una tendencia favorable con esta afirmación. Igualmente, el CNMFJ estuvo completamente de acuerdo con esta afirmación.

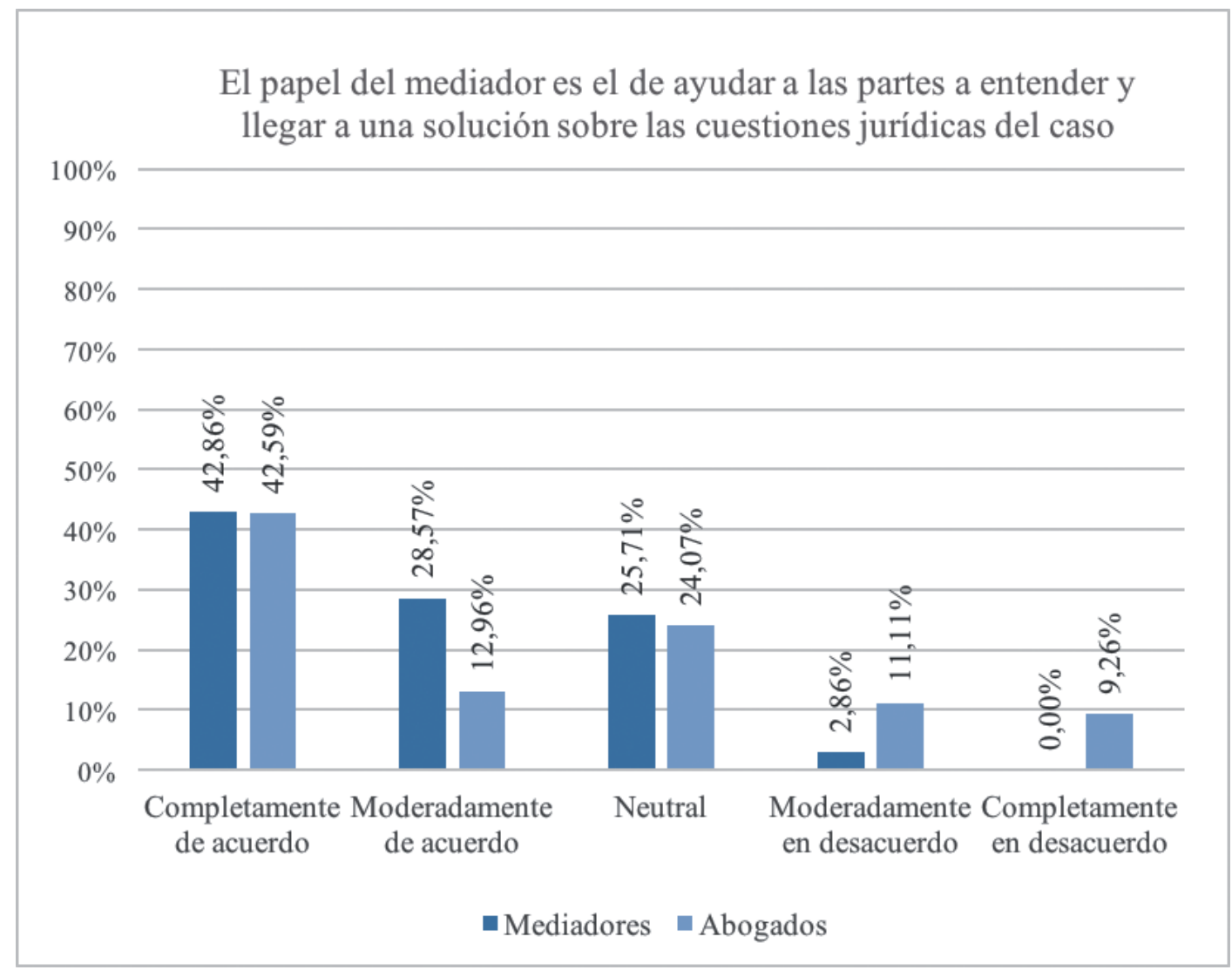

Ilustración 7: Gráfico comparativo de barras de las respuestas de los mediadores y abogados a la pregunta "El papel del mediador es el de ayudar a las partes a entender y llegar a una solución sobre las cuestiones jurídicas del caso".

Esto quiere decir que, tanto para abogados como mediadores las cuestiones legales forman parte de la mediación y que el mediador debe contribuir con la resolución de la disputa jurídica específica. 
Adicionalmente, la mayoría de mediadores y abogados consideran que es una práctica aceptable que las partes realicen ofertas y contraofertas de valores monetarios durante la mediación. El 82,86\% de mediadores y el 79,63\% de abogados están de acuerdo con este estilo de negociación.

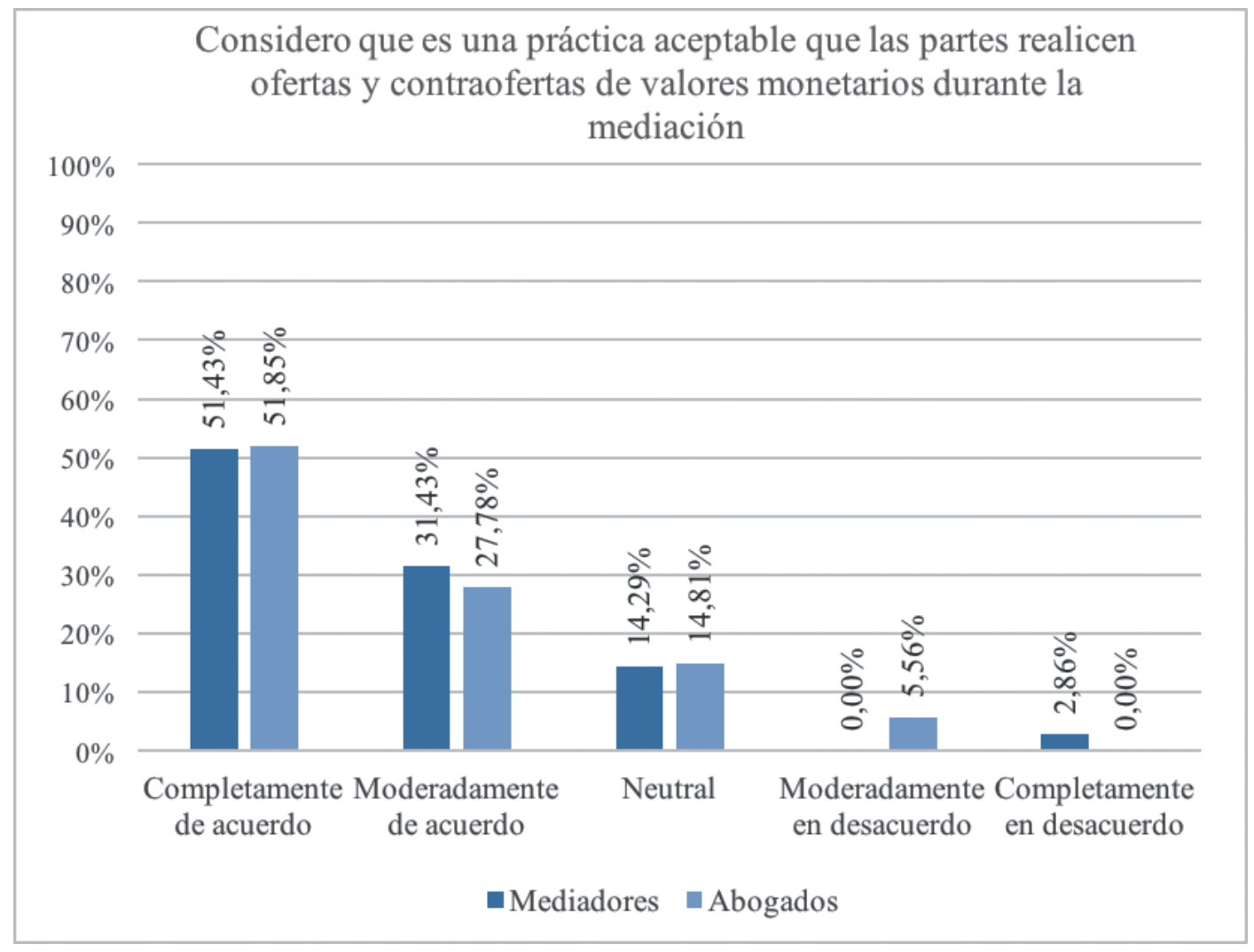

Ilustración 8: Gráfico comparativo de barras de las respuestas de los mediadores y abogados a la pregunta "Considero que es una práctica aceptable que las partes realicen ofertas y contraofertas de valores monetarios durante la mediación".

Esta pregunta tiene relación con el modelo de negociación distributiva que deja de lado los intereses, las emociones y las causas del conflicto para enfocarse solamente en un intercambio de ofertas y demandas de contenido monetario. Este modelo de negociación es propio de una definición estrecha del problema. 
Al respecto, el CNMFJ manifestó estar completamente de acuerdo:

Conforme a la metodología de negociación, lineal, que se aplica durante la audiencia, casi siempre las partes realizan ofertas y contraofertas, sobre todo cuando se tratan temas civiles, patrimoniales o relacionados con formas de cumplimiento de obligaciones onerosas o de tracto sucesivo. De todas formas, el uso del regateo como una forma de llegar a un acuerdo, debe ser moderado por el mediador o mediadora, recordando a las partes respecto de los criterios objetivos o las causas que han dado lugar a la obligación, a fin de cumplir dentro de los parámetros normativos vigentes al momento del contrato y del acta de mediación.

Finalmente, al momento de preguntar a los abogados y mediadores encuestados si consideran una técnica adecuada sacar a los abogados de la sala de mediación, no se pudo obtener una respuesta clara que evidencie una tendencia real. El 40\% de mediadores (incluyendo la postura oficial del CNMFJ) y el $44,45 \%$ de abogados se encuentran en desacuerdo; mientras que un porcentaje representativo de mediadores y abogados (34,29\% y 24,07\%, respectivamente) se encuentran en indecisión; $y$, finalmente el $25,72 \%$ de mediadores y el 31,48\% de abogados se encuentran de acuerdo con la práctica. 


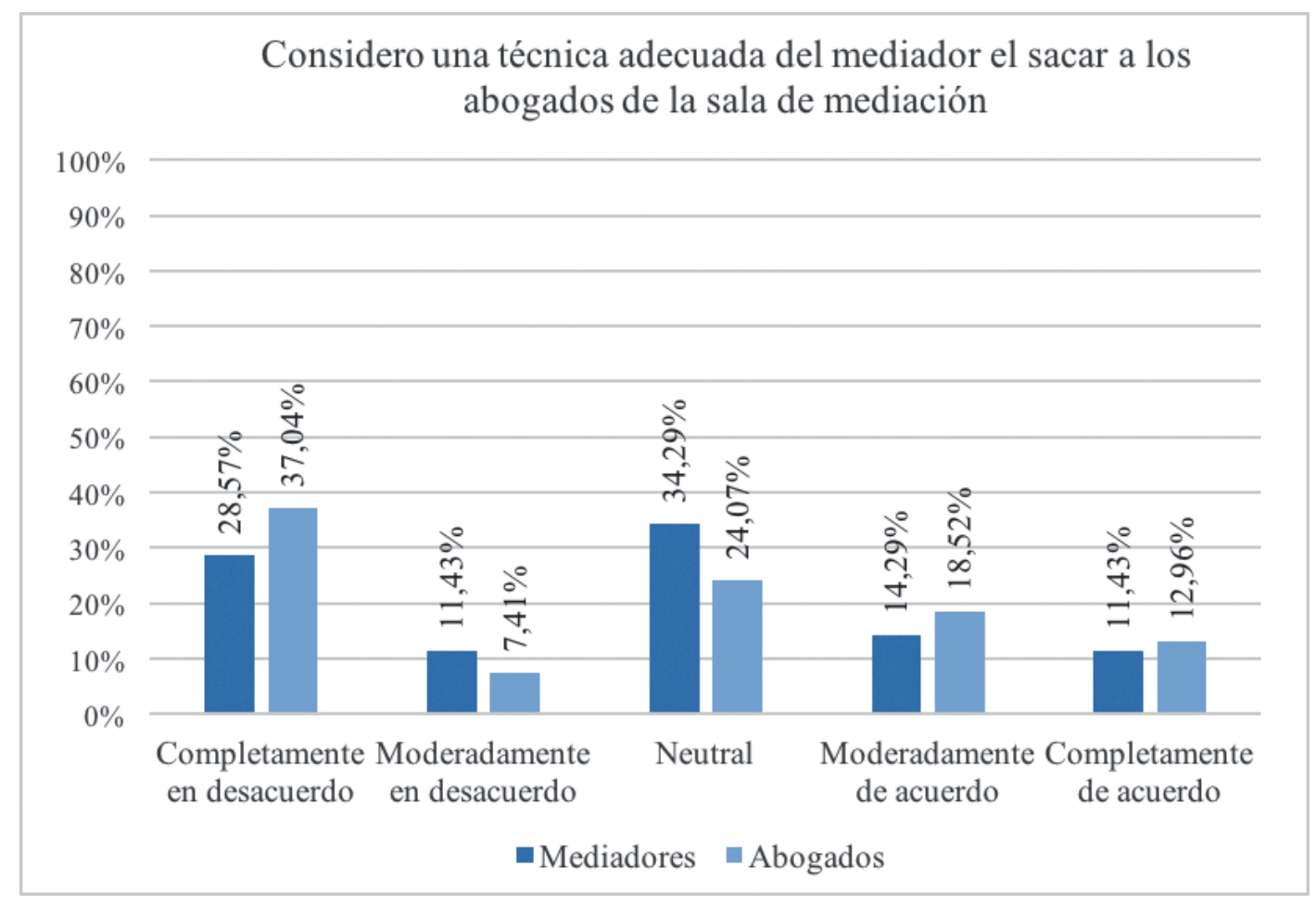

Ilustración 9: Gráfico comparativo de barras de las respuestas de los mediadores y abogados a la pregunta "Considero una técnica adecuada sacar a los abogados de la sala de mediación".

A pesar de la dispersión en los resultados, al parecer existe una tendencia a considerar necesaria la presencia de los abogados en la mesa de negociación, lo que sugiere a su vez que la conversación se enfoque en los asuntos legales.

\section{- Enfoque en cuestiones que trascienden lo legal}

Ahora bien, al mismo tiempo que los encuestados estuvieron de acuerdo con tratar los temas legales, también estuvieron de acuerdo con tratar temas que van más allá del asunto legal. Así pues, el 91,43\% de mediadores y el 83,33\% de abogados encuestados están de acuerdo con observar cuestiones adicionales a las legales al momento de realizar una mediación o acudir a ella. 


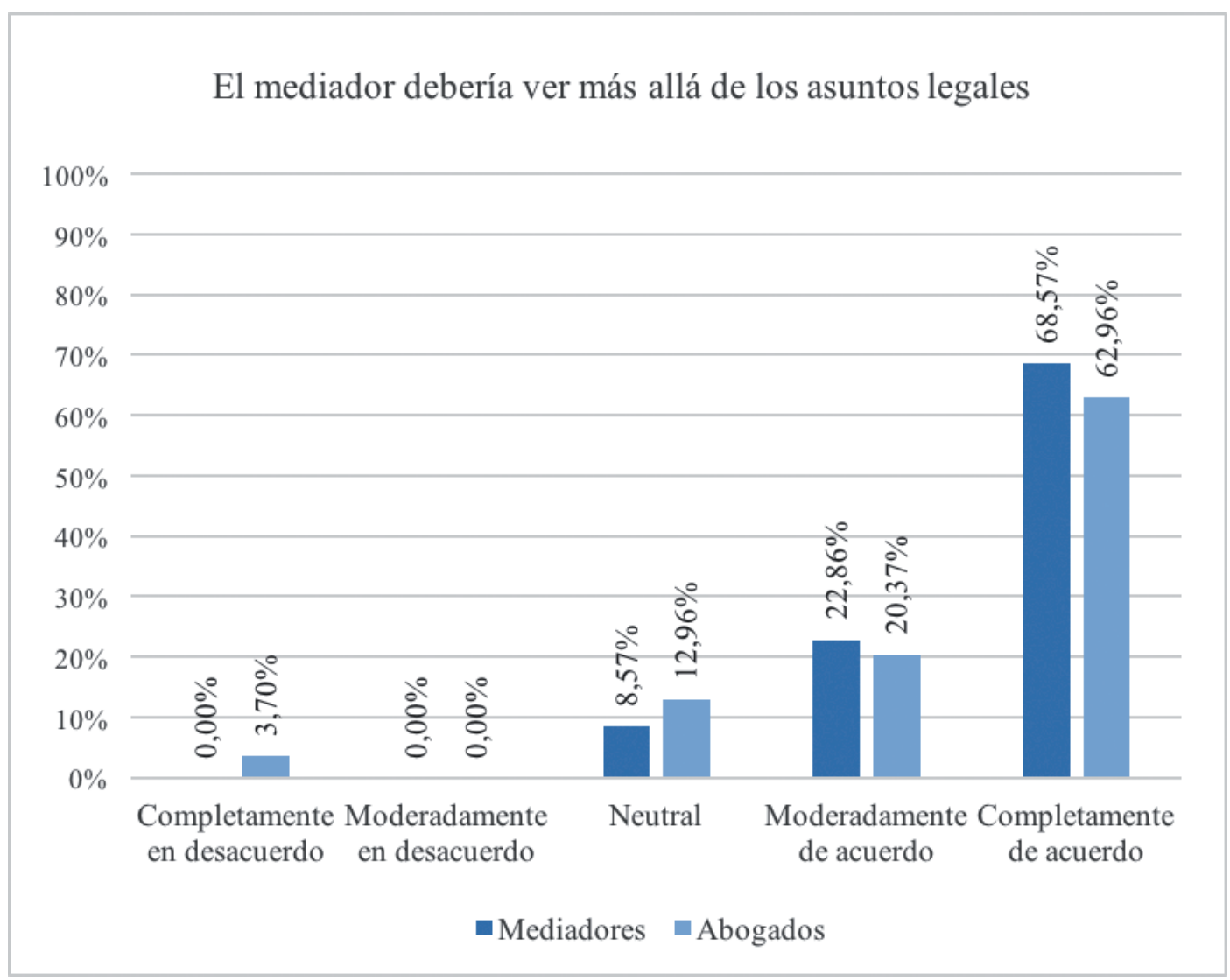

Ilustración 10: Gráfico comparativo de barras de las respuestas de los mediadores y abogados a la pregunta "El mediador debería ver más allá de los asuntos legales".

Aquello refleja una fuerte y marcada tendencia a definir de manera amplia los problemas que son llevados a mediación, de manera que tome en cuenta también los intereses, las emociones y las percepciones de las partes.

De hecho, la respuesta del CNMFJ refleja una definición del problema que llega al cuarto nivel de amplitud, al decir:

el rol del mediador o mediadora va más allá de solucionar casos, se enfoca a la búsqueda de la cultura de paz [...]. [Citando] al Dr. Gustavo Jalkh, Presidente del Consejo de la Judicatura, quien manifiesta que la ecuación: un conflicto igual a un juicio no es viable ni sostenible, social ni económicamente, por lo que la mediación se constituye en una vía privilegiada que permite el fortalecimiento del tejido social y un importante ahorro de recursos que se debería invertir en el sistema judicial formal. 
De igual manera, tanto abogados como mediadores tienden a estar de acuerdo con la idea de que la percepción de las partes sobre la disputa es más relevante que la evidencia que se tenga sobre el caso. El 77,14\% de mediadores y el 57,4\% de abogados afirman estar de acuerdo con la postura mencionada.

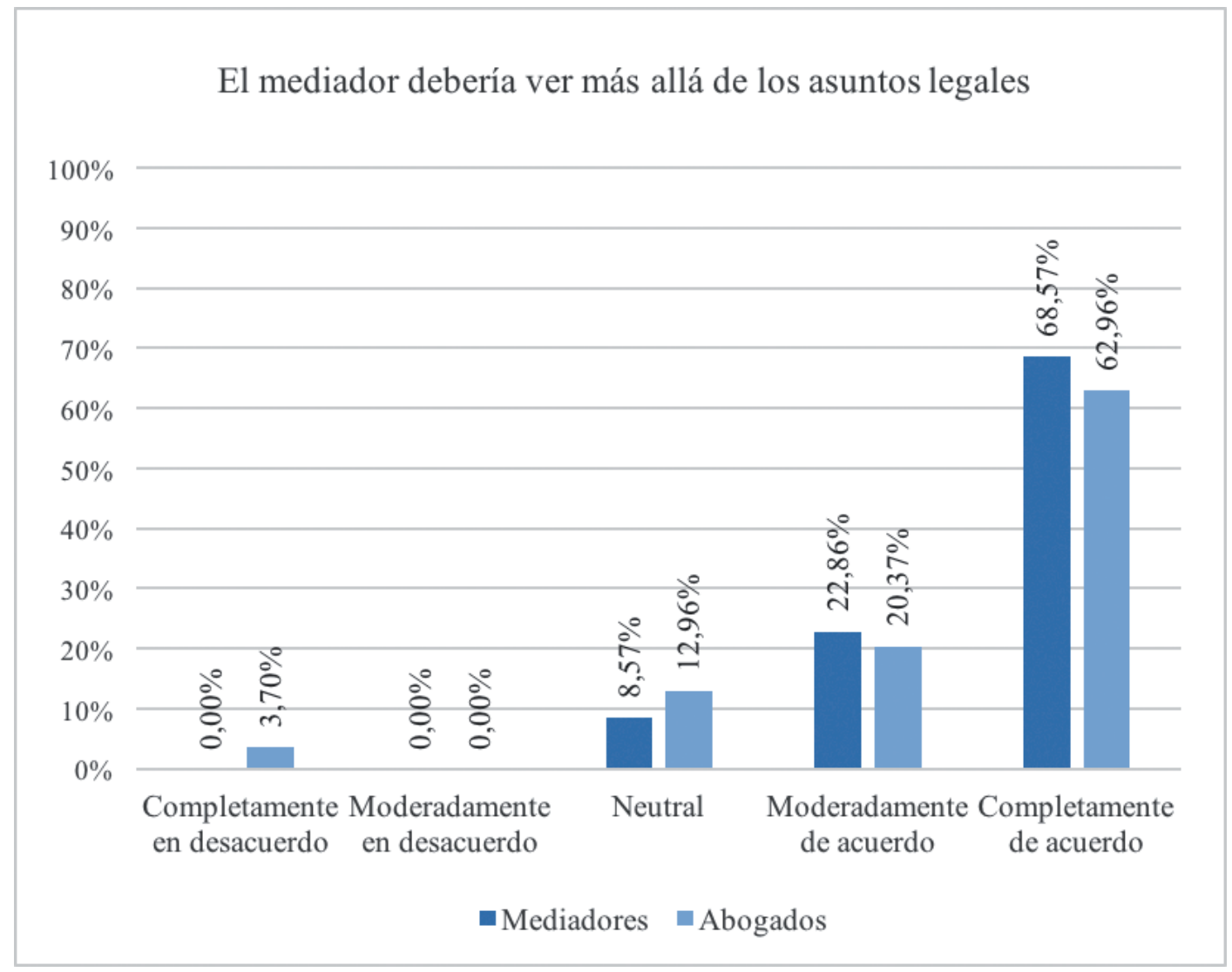

Ilustración 11: Gráfico comparativo de barras de las respuestas de los mediadores y abogados a la pregunta "La percepción de las partes acerca del conflicto es más importante que la evidencia del caso".

Esto refleja una tendencia a definir el problema de manera más amplia, pues las percepciones de las partes tendrán más valor que la prueba con la que cuenten para demostrar sus afirmaciones en un proceso judicial. Esta respuesta parece indicar que los abogados y mediadores ven a la mediación como un procedimiento que resuelve controversias cuyos matices no son exclusivamente jurídicos.

Eventualmente, esto podría implicar que ni los mediadores ni los abogados consideran los posibles riesgos, desde la perspectiva de la prueba, al acudir a los tribunales de justicia. 
Es interesante la posición del CNMFJ, quien tuvo una postura neutral reconociendo el valor que tiene el tomar en cuenta el análisis de la realidad, "lo que implica que salgan del ámbito de las percepciones, que es subjetivo, para tratar los temas en base a criterios objetivos".

\section{- Enfoque en cuestiones personales}

Al momento de definir el problema, tanto abogados como mediadores, también se ubicaron en el tercer nivel de amplitud. Así pues consideraron que la mediación debería lograr el empoderamiento de las partes, el entendimiento mutuo, y la satisfacción de intereses, por encima de una resolución jurídica concreta. El 85,71\% de mediadores y el $88,88 \%$ de los abogados están de acuerdo con incorporar estos asuntos dentro de las mediaciones.

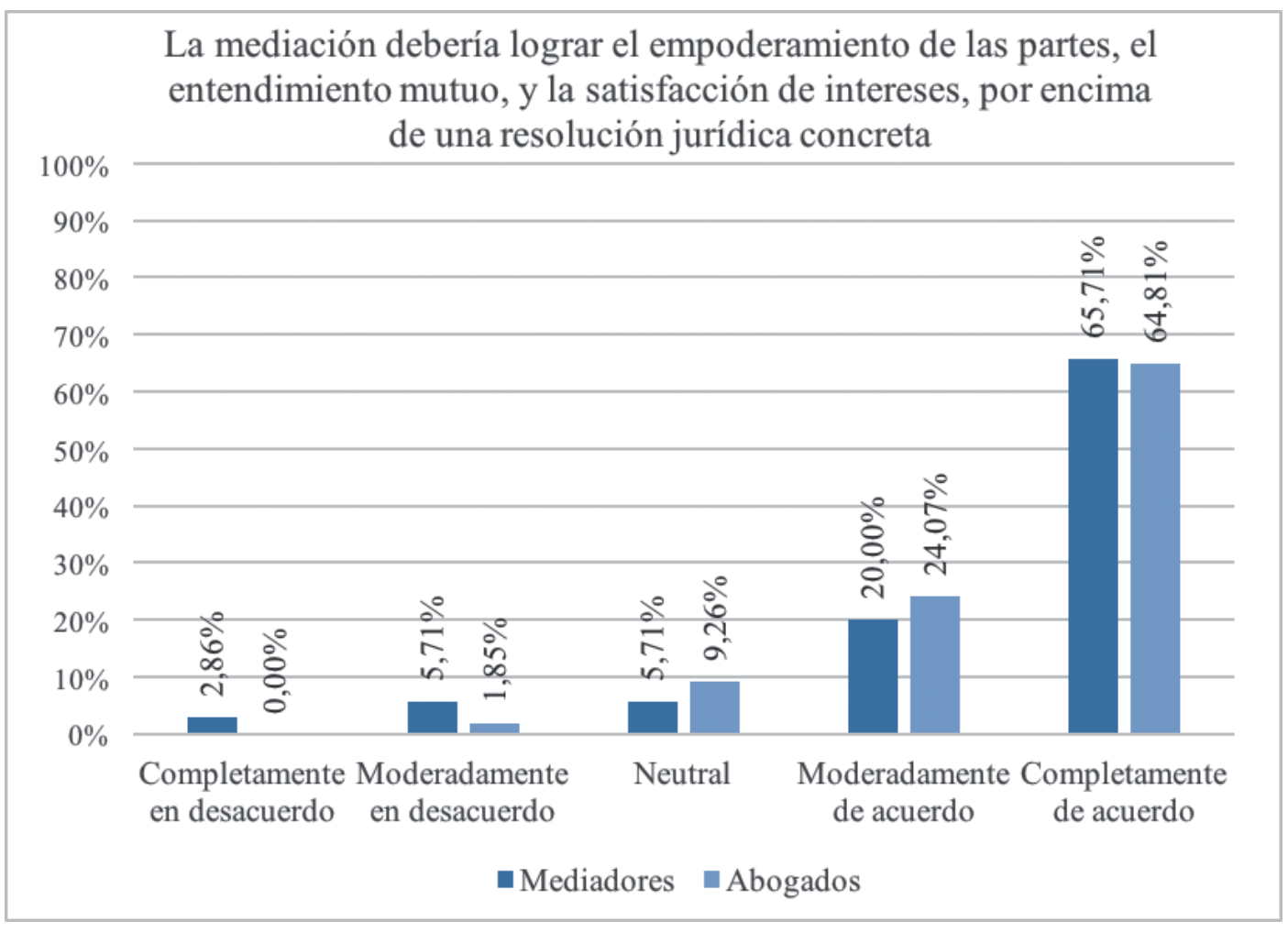

Ilustración 12: Gráfico comparativo de barras de las respuestas de los mediadores y abogados a la pregunta "La mediación debería lograr el empoderamiento de las partes, el entendimiento mutuo y la satisfacción de intereses, por encima de una resolución jurídica concreta". 
Resulta interesante la respuesta del CNMFJ quien estuvo completamente en desacuerdo, al considerar que:

[n]o son objetivos exclusivos e independientes de la mediación, el empoderamiento de las partes, el entendimiento mutuo o la satisfacción de intereses sino que, si estos objetivos se consiguen durante la mediación; la consecuencia natural y lógica es que se lleguen a acuerdos que resuelvan conflictos jurídicos concretos. Es tan importante lo uno como lo otro.

El resultado de la encuesta no arrojó una tendencia marcada con respecto a la definición del problema. Al momento de responder las preguntas, los abogados y mediadores apuntaron a definiciones estrechas y amplias del problema al mismo tiempo. Cabe resaltar la postura del CNMFJ para quien es tan importante lo uno como lo otro. Así pues, la definición del problema dependerá mucho del caso que se tiene al frente, y de cómo las partes quieran abordar el conflicto. Los mediadores parecerían moldeables a cualquiera de las tendencias de definición del problema, de suerte que podrán responder a las expectativas que las partes y sus abogados tengan sobre esto caso por caso.

\subsection{Las orientaciones de la mediación en la ciudad de Quito}

A través de la encuesta realizada se obtuvieron dos gráficos de dispersión que reflejan la orientación general tanto de abogados como de mediadores. Estos resumen sus preferencias con respecto a los estilos y la definición del problema. En ambos gráficos de dispersión se evidenciará, entonces, una marcada tendencia hacia el estilo evaluativo, y una falta de claridad en cuanto a la definición del problema. Dichos resultados se encuentran graficados de la siguiente manera: 


\section{Resultados de las encuestas realizados a mediadores}

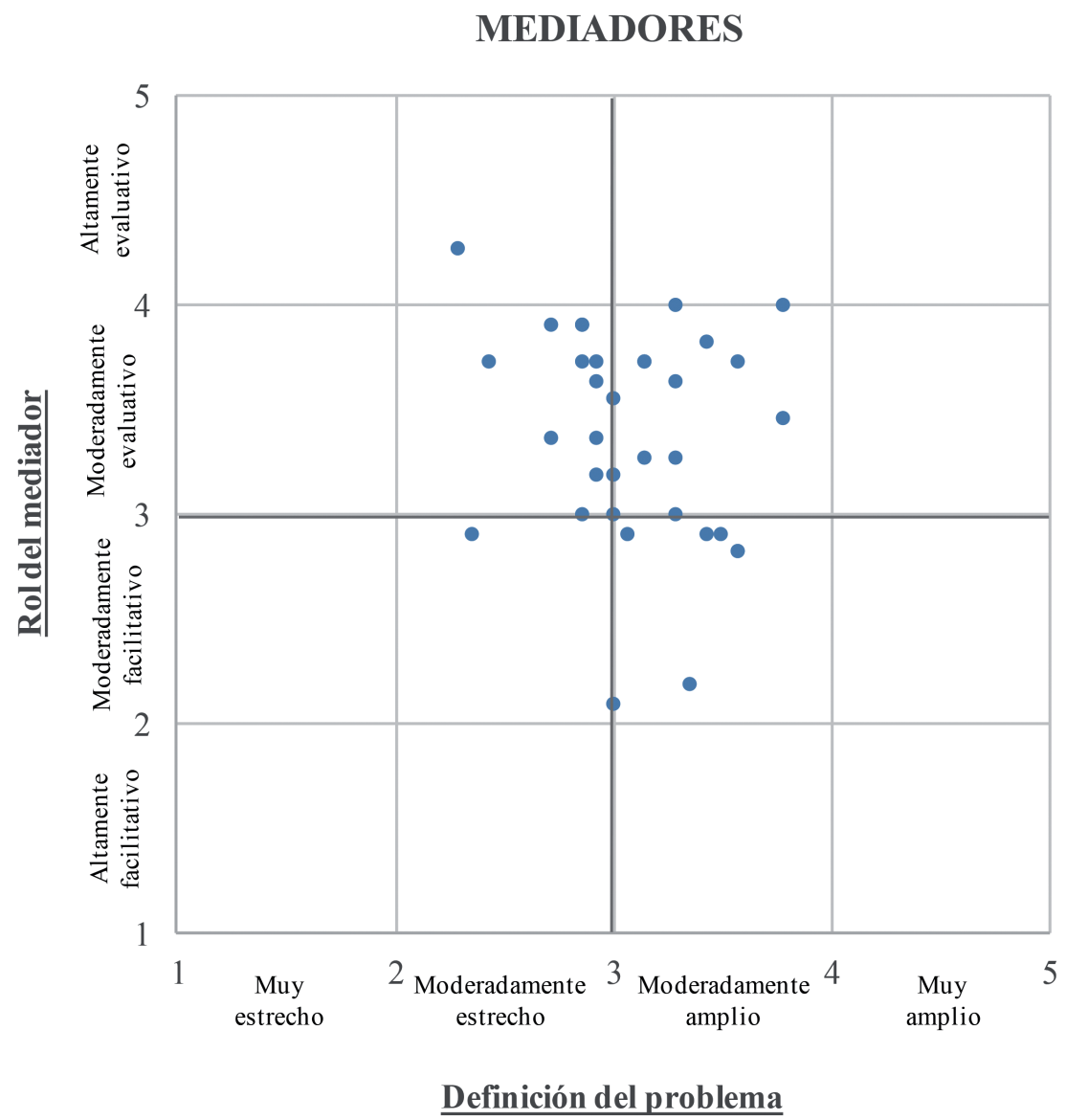

Ilustración 13: Cuadrante en el que es posible evidenciar la orientación de los mediadores encuestados.

Este cuadrante revela una clara tendencia por parte de los mediadores hacia el estilo evaluativo, pues la amplia mayoría de los resultados se encuentran ubicados en la parte superior del cuadrante. En cuanto a la definición del problema, este gráfico nos demuestra que no existe una tendencia clara sobre cómo definirlo, ello debido a que los resultados se encuentra dispersos a lo largo del eje horizontal. 
- Resultados de las encuestas realizados a abogados

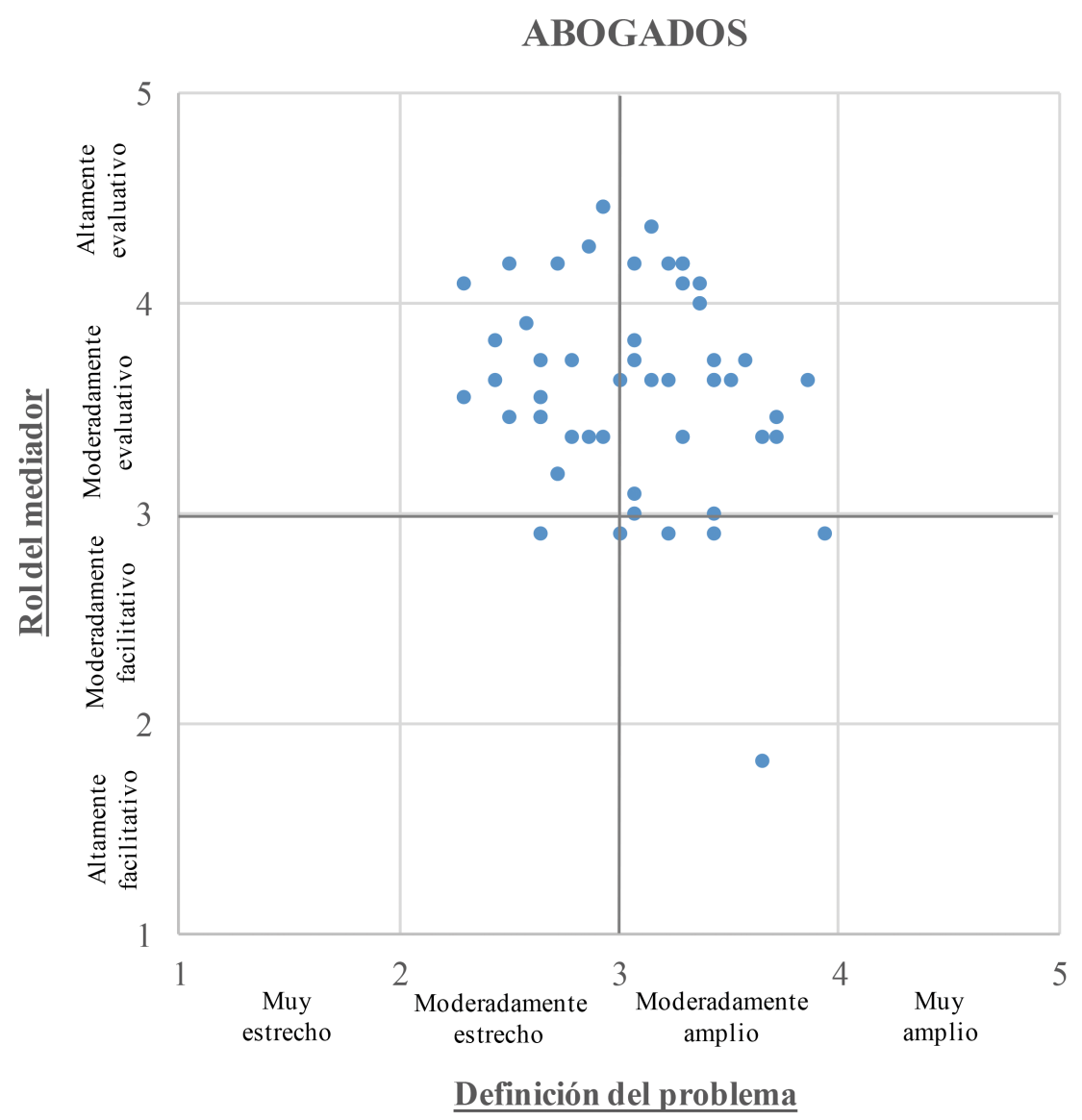

Ilustración 14: Cuadrante en el que es posible evidenciar la orientación que prefieren los abogados encuestados.

En cuanto a los abogados, la tendencia hacia un estilo evaluativo es aún más clara. De hecho, salvo una excepción, los únicos puntos que se encuentran por debajo del eje horizontal están sumamente cerca del límite. Respecto a la definición del problema, al igual que lo ocurrido con los mediadores, no existe una tendencia definida, puesto que los resultados se encuentra dispersos en la parte izquierda y derecha del cuadrante. 


\subsection{Otras técnicas procedimentales relevantes empleadas en la ciudad de Quito}

Otro de los componentes de la encuesta realizada apunta a identificar otras técnicas procedimentales relevantes utilizadas en la mediación, tales como la utilización de reuniones privadas y el contacto del mediador con las partes antes de la audiencia.

\section{- Sobre las reuniones privadas}

Algunos modelos de mediación se realizan exclusivamente en una audiencia conjunta (especialmente, las mediaciones en donde la definición del problema es amplia); otros, en cambio, se llevan a cabo solamente en reuniones privadas (especialmente las mediaciones orientadas a estilos evaluativos con definición estrecha). Finalmente, otros modelos combinan tanto sesiones conjuntas como privadas para tener un rango mayor de técnicas.

De los encuestados, el 62,86\% de mediadores y el $43,75 \%$ de abogados están de acuerdo con utilizar reuniones privadas con las partes antes de las reuniones conjuntas para ayudarlas a entender las debilidades de su caso. A su vez, el 28,57\% de los mediadores y el $43,75 \%$ de abogados están en desacuerdo con esta práctica. 


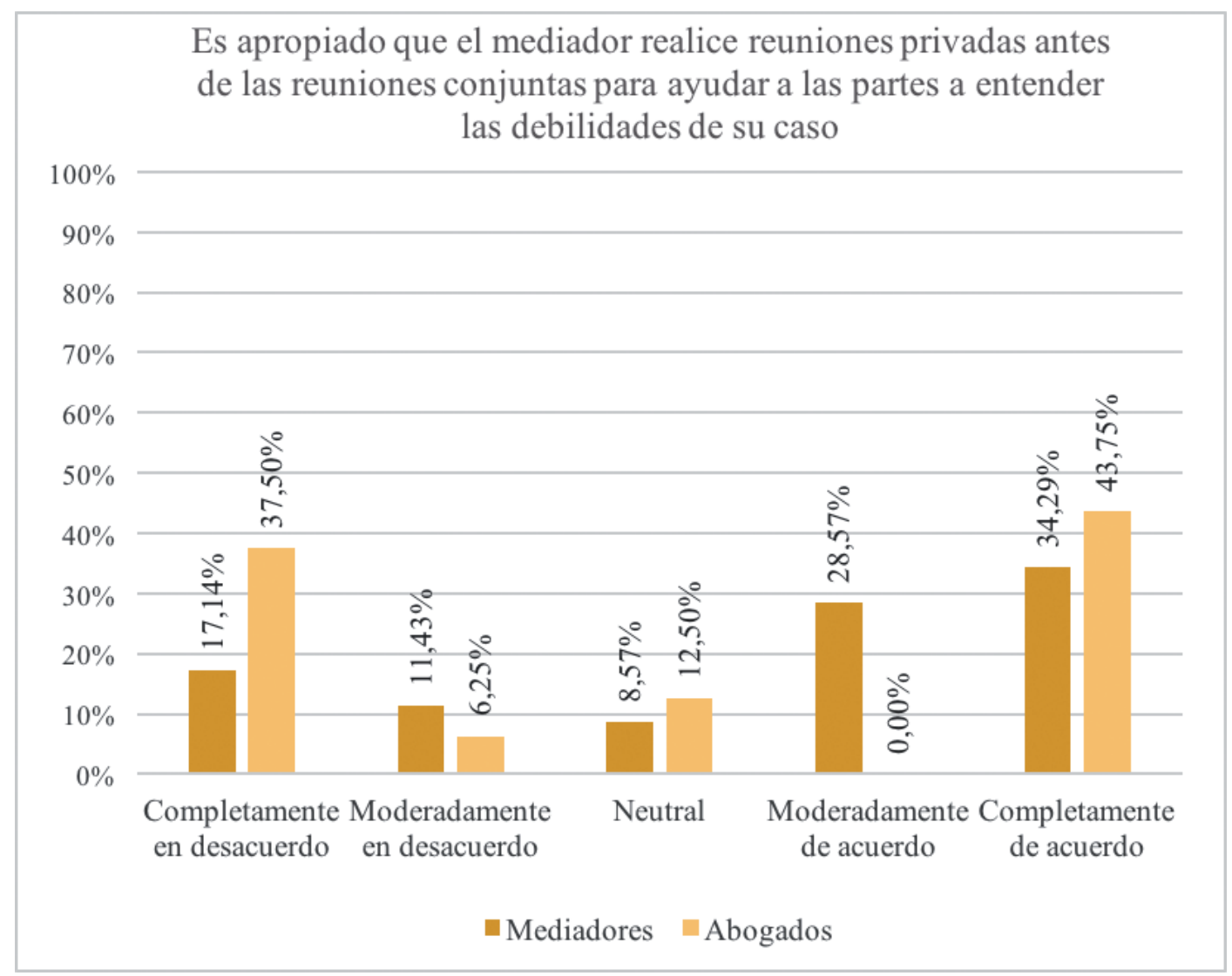

Ilustración 15: Gráfico comparativo de barras de las respuestas de los mediadores y abogados a la pregunta "Es apropiado que el mediador realice reuniones privadas antes de las reuniones conjuntas para ayudar a las partes a entender las debilidades de su caso".

Consecuentemente, no existe consenso sobre la pertinencia del uso de reuniones privadas. De hecho, los porcentajes de abogados de acuerdo y en desacuerdo con el uso de la práctica son idénticos, lo que indica que sus preferencias no son uniformes. Los mediadores, en cambio, sí manifiestan una tendencia favorable al uso de reuniones privadas. Por su parte, el CNMFJ está de acuerdo con la afirmación, motivando que:

Las reuniones por separado son importantes y muy útiles, dependiendo del caso, sin embargo, no son la herramienta principal de la mediación. Por lo que, el mediador o mediadora, deberá aplicar esta herramienta, tantas veces cuantas fuere necesaria, pero lo previsto es que las partes puedan conversar entre ellas porque para eso han acudido voluntariamente a la audiencia de mediación. 
Estas respuestas parecen reflejar la flexibilidad en el manejo de la mediación.

- Sobre el contacto del mediador con las partes antes de la audiencia

En los Estados Unidos, la mediación incluye una etapa de convening ${ }^{71}$, lo que implica que el mediador o un asistente suyo 'ponga la mesa' para negociar. Para el efecto, se toma contacto con las partes de manera previa a la audiencia para, entre otros, verificar quiénes asistirían, confirmar la fecha y el lugar, definir los temas a tratar, acordar la posibilidad de presentar escritos con las posiciones legales de las partes, determinar cómo se llevará a cabo la mediación (si habrán audiencias conjuntas, presentaciones de las partes u otras). Esta fase de premediación no ha sido acogida del todo en nuestra práctica. El 42,86\% de mediadores y el $22,58 \%$ de abogados están de acuerdo con que el mediador tenga contacto con las partes antes de la primera audiencia. Por el contrario, el $45,71 \%$ de mediadores y el $64,52 \%$ de abogados no concuerdan con esta práctica. 


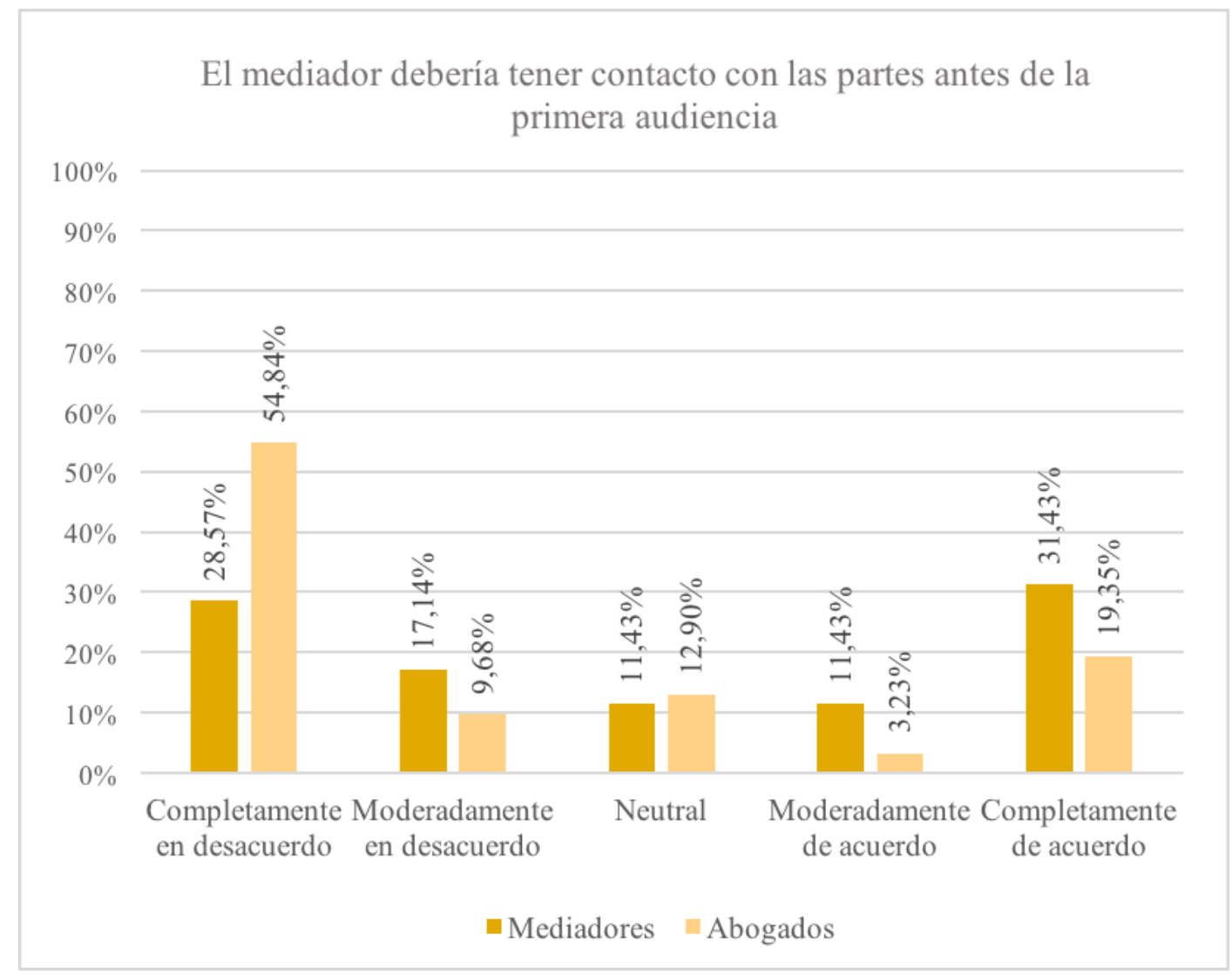

Ilustración 16: Gráfico comparativo de barras de las respuestas de los mediadores y abogados a la pregunta "El mediador debería tener contacto con las partes antes de la primera audiencia".

Probablemente estos resultados tienen que ver con el temor de comprometer la neutralidad del mediador. Precisamente, el CNMFJ ha manifestado estar completamente en desacuerdo con la afirmación, puesto que considera que "es una misión fundamental del mediador velar por la neutralidad e imparcialidad en el ejercicio de su tarea durante todo el procedimiento de mediación". Así, teme que el contacto previo con las partes pueda resultar perjudicial y atente contra la neutralidad e imparcialidad del mediador, argumentando que:

[N]o se considera útil que el mediador o mediadora mantenga contacto con las partes antes de la primera audiencia, salvo una llamada telefónica o correo electrónico que está previsto que se gestionen con la única finalidad de confirmar la asistencia de las partes a la audiencia de mediación. 


\section{COnClusiones}

Habiendo transcurrido ya 20 años de la promulgación de la Ley de Arbitraje y Mediación, el Ecuador ha generado una práctica importante de mediación. La presente investigación buscó descifrar la orientación predominante en mediación tanto de los mediadores cuanto de los abogados que concurren a las audiencias. De esta orientación dependerán muchas de las técnicas que se utilicen dentro de la mediación.

La orientación de la mediación se da en función del estilo del mediador (facilitativo o evaluativo) y de la definición del problema (estrecho o amplio). En su origen la mediación fue concebida como un espacio en donde el mediador facilita (estilo facilitativo) la resolución de un conflicto que va mucho más allá de las posiciones de las partes para centrarse en los intereses (definición amplia). Con el tiempo y la incorporación más activa de los abogados en los procedimientos de mediación, la práctica ha ido transformando esta visión pura para dar paso a estilos más evaluativos y definiciones más estrechas del problema. Hoy en día los mediadores tienen una amplia gama de estrategias y técnicas que pueden utilizar para lograr la resolución de la controversia en diferentes niveles.

La presente investigación realizó una encuesta a mediadores y abogados de la ciudad de Quito, para generar un planteamiento inicial sobre cuál parecería ser la orientación que tienen hacia la mediación. El resultado arroja que quienes contestaron la encuesta demuestran una clara tendencia a un estilo evaluativo, siendo los abogados aún más evaluativos que los mediadores. La visión institucional del CNMFJ mantiene un compromiso con un estilo más puro de mediación facilitativo.

Igualmente, los encuestados no demostraron una tendencia marcada con respecto a la definición del problema, evidenciando una total flexibilidad sobre los elementos que pueden ser parte de la conversación dentro de una audiencia de mediación. 
Finalmente, se constatan ciertas discordancias entre las expectativas que tienen los abogados con la práctica de los mediadores. Igualmente, quedan temas que se irán revelando con la práctica, como la mayor especialización de nuestra profesión en el futuro, lo que encerrará la fase de premediación y el énfasis que se le dará, y la posible utilización de sesiones privadas por sobre las conjuntas. El tiempo y el desarrollo de la mediación moldeará estos temas hacia delante.

* Para acceder al contenido de la encuesta y a los resultados generales ingrese a: www.pactum.com.ec 